\title{
An assessment of in-tube flow boiling correlations for ammonia-water mixtures and their influence on heat exchanger size
}

Kærn, Martin Ryhl; Modi, Anish; Jensen, Jonas Kjær; Andreasen, Jesper Graa; Haglind, Fredrik

Published in:

Applied Thermal Engineering

Link to article, DOI:

10.1016/j.applthermaleng.2015.09.106

Publication date:

2016

Document Version

Peer reviewed version

Link back to DTU Orbit

Citation (APA):

Kærn, M. R., Modi, A., Jensen, J. K., Andreasen, J. G., \& Haglind, F. (2016). An assessment of in-tube flow boiling correlations for ammonia-water mixtures and their influence on heat exchanger size. Applied Thermal Engineering, 93, 623-638. https://doi.org/10.1016/j.applthermaleng.2015.09.106

\section{General rights}

Copyright and moral rights for the publications made accessible in the public portal are retained by the authors and/or other copyright owners and it is a condition of accessing publications that users recognise and abide by the legal requirements associated with these rights.

- Users may download and print one copy of any publication from the public portal for the purpose of private study or research.

- You may not further distribute the material or use it for any profit-making activity or commercial gain

- You may freely distribute the URL identifying the publication in the public portal 


\title{
An assessment of in-tube flow boiling correlations for ammonia-water mixtures and their influence on heat exchanger size
}

\author{
Martin Ryhl Kærn",*, Anish Modia , Jonas Kjær Jensenª, Jesper Graa Andreasen ${ }^{\mathrm{a}}$, Fredrik \\ Haglind $^{\text {a }}$ \\ ${ }^{a}$ Department of Mechanical Engineering, Technical University of Denmark, Nils Koppels Allé Bygn. 403, DK-2800 \\ Kgs. Lyngby, Denmark
}

\begin{abstract}
Heat transfer correlations for pool and flow boiling are indispensable for boiler design. The correlations for predicting in-tube flow boiling heat transfer of ammonia-water mixtures are not well established in the open literature and there is a lack of experimental measurements for the full range of composition, vapor qualities, fluid conditions, etc.

This paper presents a comparison of several flow boiling heat transfer prediction methods (correlations) for ammonia-water mixtures. Firstly, these methods are reviewed and compared at various fluid conditions. The methods include: (1) the ammonia-water specific flow boiling correlations from the open literature, (2) the ammonia-water specific pool boiling correlations from the open literature extended to flow boiling by using the pure fluid correlation by Gungor and Winterton, and (3) the classical wide-boiling correlations. Secondly, their influence on the required heat exchanger size (surface area) is investigated during numerical design. For this purpose, two case studies related to the use of the Kalina cycle are considered: a flue gas based heat recovery boiler for a combined cycle power plant and a hot oil based boiler for a solar thermal power plant.

The results indicate that the nucleate boiling contribution to flow boiling is small compared to the flow boiling contribution for the investigated conditions. Furthermore, the use of the different flow boiling correlation methods resulted in evaporator size differences within $6 \%$ for the heat recovery boiler and $28 \%$ for the oil based boiler.
\end{abstract}

Keywords: Ammonia-water, Flow boiling, Heat exchanger design, Heat transfer, Kalina cycle, Modeling, Zeotropic mixture 


\section{Nomenclature}

2 Roman

3 Bo boiling number

$4 \quad D$ mass diffusivity $\left[\mathrm{m}^{2} \mathrm{~s}^{-1}\right]$

${ }_{5} d$ diameter [m]

$6 \quad E_{0}$ enhancement factor

$7 \quad F$ two-phase multiplier

${ }_{8} F_{c}$ pool boiling mixture correction factor

9 $G$ mass flux $\left[\mathrm{kg} \mathrm{m}^{-2} \mathrm{~s}^{-1}\right]$

$10 \quad g$ gravitational acceleration $\left[\mathrm{m} \mathrm{s}^{-2}\right]$

${ }_{11} h_{\mathrm{LV}}$ latent heat of evaporation $\left[\mathrm{kJ} \mathrm{kg}^{-1}\right]$

$12 h$ heat transfer coefficient [ $\mathrm{W} \mathrm{m}^{-2} \mathrm{~K}^{-1}$ ]

${ }_{13} h_{I}$ ideal heat transfer coefficient $\left[\mathrm{W} \mathrm{m}^{-2} \mathrm{~K}^{-1}\right]$

${ }_{14} \quad k$ thermal conductivity [ $\mathrm{W} \mathrm{m}^{-1} \mathrm{~K}^{-1}$ ]

${ }_{15} p$ pressure $[\mathrm{Pa}]$

16 Pr Prandtl number

$17 q$ heat flux $\left[\mathrm{W} \mathrm{m}^{-2}\right]$

18 Re Reynolds number

$19 \quad S$ suppression factor

20 $T$ temperature $[\mathrm{K}]$

${ }_{21} \quad X$ vapor quality [-]

$22 \quad Z$ bulk mass fraction of ammonia

23 $\quad X_{\mathrm{tt}}$ Lockhart-Martinelli parameter

$24 x, \tilde{x}$ liquid mass and mole fraction of ammonia

$25 y, \tilde{y}$ vapor mass and mole fraction of ammonia

*Corresponding author. Tel.: +45 4525 4121; fax: +45 45935215.

Email address: pmak@mek.dtu.dk (Martin Ryhl Kærn) 
1 Greek

$2 \quad \alpha$ thermal diffusivity $\left[\mathrm{m}^{2} \mathrm{~s}^{-1}\right]$

$3 \quad \rho$ density $\left[\mathrm{kg} \mathrm{m}^{-3}\right]$

${ }_{4} \quad \Delta T_{\mathrm{bp}}$ boiling range $[\mathrm{K}]$

${ }_{5} \Delta T_{I}$ ideal wall superheat $[\mathrm{K}]$

$6 \quad \mu$ dynamic viscosity [Pa s]

$7 \sigma$ surface tension $\left[\mathrm{N} \mathrm{m}^{-1}\right]$

8 Subscripts

9 bub bubble point

$10 \quad c$ cold

11 dew dew point

$12 h$ hot

13 L liquid

14 cb convective boiling

$15 \mathrm{nb}$ nucleate boiling

$16 \quad S$ saturation

$17 \mathrm{~V}$ vapor

18 Abbreviations

19 EV evaporator

20 EC economizer

21 HRB heat recovery boiler

22 LL linear law

23 $\mathrm{MP}$ mixture properties

24 OBB oil based boiler

25 RSD relative standard deviation

26 SH superheater 


\section{Introduction}

The ammonia-water mixture has been used as working fluid for decades in various applications utilizing low-grade heat such as absorption refrigeration systems, heat pumps and power cycles. Reliable heat transfer correlations are always needed for the design of heat exchangers in such systems as both the plant efficiency and the cost (heat exchangers size) are important when comparing the economic feasibility.

The ammonia-water mixture is a zeotropic mixture having a non-isothermal phase-change. One of the main benefits of the non-isothermal phase-change is the possibility of temperature matching with the heat source/sink temperature profiles, thus decreasing thermal irreversibilities and improving plant efficiency compared to pure fluids. On the other hand, the required heat transfer surface area increases because of the reduced temperature difference between the working fluid and the heat source/sink. In addition, the mixture flow boiling heat transfer coefficients are typically smaller than their pure counterparts $[2,3]$. The resulting area increase influence negatively in the eventual economic advantage of a more effective plant [4] and it may result in an unfeasible plant economy. The heat transfer degradation in the nucleate boiling region is mainly due to the additional mass transfer resistance, while in the convective boiling region, it is mainly due to the changes in thermodynamic and transport properties [2].

The thermodynamic properties of ammonia-water mixtures are experimentally established [5] and may be accessed by databases such as REFPROP 9.12 [6]. The transport properties of ammonia-water mixtures are less established and different experimental sources show remarkable inconsistencies [7]. The influence of using different transport property methods for the estimation of viscosity and thermal conductivity of ammonia-water mixtures have recently been evaluated during numerical heat exchanger design [8]. The results suggested that the different transport property methods, traditionally used for the ammonia-water mixtures, show small variation in the estimated heat exchanger sizes. Although the heat exchanger size shows very little sensitivity towards the different transport property estimation methods, it remains to assess the sensitivity of the various flow boiling heat transfer correlations on the predicted heat exchanger size.

Only two in-tube flow boiling heat transfer correlations were found developed specifically for 
ammonia-water mixtures $[9,10]$ in the open literature. These two correlations employ the simple flow boiling correlation by Mishra et al. [11] but with very different constants. Three other studies on flow boiling of ammonia-water mixtures have been found [12-14], however these consider plate heat exchangers, whose heat transfer correlations are not applicable in the general case of in-tube flow boiling. Additionally, the pressures in all these studies are well below that typically encountered in Kalina cycle boilers. From the low availability in the open literature, it is clear that general heat transfer prediction methodologies for wide boiling mixtures (e.g. ammonia-water) must be used in order to predict the flow boiling heat transfer of ammonia-water mixtures and thus the evaporator size. To the authors' knowledge, no previous analysis has been conducted about the influence of using different flow boiling heat transfer correlations for ammonia-water mixtures.

This paper compares a set of various in-tube flow boiling heat transfer correlations applied to the ammonia-water mixture. The two aforementioned ammonia-water specific flow boiling correlations $[9,10]$ are compared with two classical wide-boiling correlations [2, 15]. Additionally, a few ammonia-water specific pool boiling correlations are extended to flow boiling following the approach outlined by Palen [16] and Thome [17], using the pure fluid flow boiling correlation by Gungor and Winterton [1]. Then the required evaporator surface area is investigated using each correlation during numerical design. The objective is to clarify whether the different heat transfer correlations have a significant influence on the designed evaporator size. Two Kalina cycle case studies are considered for this purpose: a flue gas based heat recovery boiler (HRB) for a combined cycle power plant and a hot oil based boiler (OBB) for a solar thermal power plant. The two cases represent boilers with either poor or good heat transfer characteristics on the hot fluid side. The boiler is usually the largest component in the Kalina cycle, taking up about half of the total surface area and destroying the most exergy [18]. In total, 7 correlations are used during the numerical design and simulated at different ammonia mass fractions and pressures in order to include several design conditions.

The contributions to state-of-the-art of the paper are a thorough review of applicable flow boiling correlations for ammonia-water mixtures, and a comprehensive comparison of these correlations and their individual effect on the required heat exchanger size (surface area) during numerical design of the two Kalina cycle case studies. 
The outline of the paper is as follows: Section 2 introduces the different correlations. Section 3 describes the design models of the two case studies. Section 4 presents the results constituting the estimated heat exchanger sizes when using the different flow boiling heat transfer correlations. Finally, the results are discussed in Section 5 and followed up by the conclusions in Section 6 .

\section{Literature survey}

Heat transfer correlations for pool boiling and flow boiling of binary mixtures are widely available for various organic mixtures, aqueous solutions and cryogenic fluids, and have been researched and reviewed by many [3,15, 17, 19-22]. Such correlations are generally developed by modifying existing pure fluid correlations to account for mixture effects such as the liquid mass diffusion in the nucleate boiling region, a phenomenon absent in pure fluids. The liquid mass diffusivity is typically an order of magnitude smaller than the liquid thermal diffusivity and controls the nucleate boiling process [3]. The more volatile component becomes depleted in the surrounding liquid of a vapor bubble, causing a local increase of the boiling point at the liquid/vapor interface and loss of wall superheat. In contrast, the convective boiling contribution is typically well predicted with that in a pure fluid flow boiling correlation using mixture thermophysical properties. Nevertheless, the various heat transfer correlations for binary mixtures are generally mixture specific, and are only valid within the data bank limits from which they were developed [3].

Several studies have been conducted on pool boiling of ammonia-water mixtures while only a few studies have considered flow boiling. Also in these studies, the main aim was to develop better correlations to predict the boiling heat transfer by modifying already existing pure fluid correlations. However, the pressures in these experiments ( $p<15$ bar) are much lower than those of interest in Kalina cycles [18, 23, 24], which may be supercritical with respect to pure ammonia ( $p>113 \mathrm{bar}, T>132.3^{\circ} \mathrm{C}$ ). In such conditions, the pure ammonia nucleate boiling coefficient cannot exist and many mixture heat transfer correlations fail to compute the ideal heat transfer coefficient, see Equation 7.

The current work is concerned with in-tube flow boiling of ammonia-water mixtures. However, both flow boiling and nucleate pool boiling have been considered. The latter is useful for flow boiling also as pointed out by Thome [17]: any existing pure fluid flow boiling correlation may 
be modified in the nucleate boiling contribution to flow boiling by using the pool boiling mixture correction factor. As examples Thome [17] showed how to apply the pool boiling mixture correlation (Thome and Shakir [25]) in the pure fluid flow boiling correlations by Gungor and Winterton $[1,26]$. Moreover, indefinite correlation combinations may be chosen by the correlation developer to fit the flow boiling data bank best, and errors become induced by both the failure to predict the nucleate boiling mixture correction as well as the failure of the general pure fluid correlation.

The aim of this literature survey is to establish a number of suitable flow boiling correlations for the ammonia-water mixture.

\subsection{Flow boiling of ammonia-water mixtures}

Rivera and Best [9] were the first authors to conduct flow boiling experiments of ammoniawater mixtures. They measured the heat transfer coefficient in a vertical smooth tube $(d=$ $25.8 \mathrm{~mm}$ ) at ammonia mass fractions from 0.38 to 0.48 , pressures from 9.4 to $12.4 \mathrm{bar}$, mass fluxes from 4.2 to $9.0 \mathrm{~kg} \mathrm{~m}^{-2} \mathrm{~s}^{-1}$ and heat fluxes from 11.2 to $18.1 \mathrm{~kW} \mathrm{~m}^{-2}$. No information was given on the vapor quality range. They argued that the flow boiling correlation by Mishra et al. [11] is advantageous, when there is a lack of transport property information available, e.g. ammonia-water mixtures. Hence, the Mishra et al. [11] equation was used to correlate their data:

$$
h=C h_{\mathrm{L}}\left(\frac{1}{X_{\mathrm{tt}}}\right)^{m} \mathrm{Bo}^{n}
$$

where $C, m$ and $n$ were modified to be $65,0.5$ and 0.15 , respectively. $h_{\mathrm{L}}$ is the liquid convective heat transfer coefficient, estimated by the Dittus and Boelter [27] correlation, $X_{\mathrm{tt}}$ is the LockhartMartinelli parameter and Bo is the boiling number, all defined by:

$$
\begin{gathered}
h_{\mathrm{L}}=\frac{k_{\mathrm{L}}}{d}\left[0.023 \operatorname{Re}_{\mathrm{L}}^{0.8} \operatorname{Pr}_{\mathrm{L}}^{0.4}\right] \\
X_{\mathrm{tt}}=\left(\frac{1-X}{X}\right)^{0.9}\left(\frac{\rho_{\mathrm{V}}}{\rho_{\mathrm{L}}}\right)^{0.5}\left(\frac{\mu_{\mathrm{L}}}{\mu_{\mathrm{V}}}\right)^{0.1} \\
\mathrm{Bo}=\frac{q}{G h_{\mathrm{LV}}}
\end{gathered}
$$

where $k, \rho, \mu$ and $X$ are the thermal conductivity, density, dynamic viscosity and vapor quality, respectively, Re and Pr are the Reynolds and Prandtl numbers, $G$ is the mass flux (or mass velocity), 
$q$ is the heat flux, $d$ is the diameter, and $h_{\mathrm{LV}}$ is the latent heat of evaporation. Furthermore, subscripts $L$ and $V$ denote the saturated liquid and vapor, respectively. The liquid Reynolds number is defined in terms of the liquid mass flux $\left(\operatorname{Re}_{\mathrm{L}}=G(1-X) d / \mu_{\mathrm{L}}\right)$.

The correlation was shown to predict the experimental data with an average deviation of $25 \%$. Additionally, the nucleate boiling was shown to be suppressed at high values of $X_{\mathrm{tt}}^{-1}$ (independence of heat flux). Despite the simplicity, the Mishra et al. [11] correlation shows a major drawback as the constant and exponents in Equation 1 change with composition. In the original work by Mishra et al. [11], the authors recommended two sets of the constant and exponents $([C, m, n]=$ $[5.64,0.23,0.05]$ and $[21.75,0.29,0.23])$ at two different compositions for the R12-R22 mixture. Moreover, Celata et al. [28] showed the inadequacy of the Mishra et al. [11] correlation as more than $50 \%$ of their data was predicted with an error of more than $35 \%$.

Khir et al. [10] performed flow boiling experiments with ammonia-water in a vertical stainless steel co-axial tube $(d=28 \mathrm{~mm})$. Three ammonia mass fractions $(0.42,0.55$ and 0.61$)$, three mass fluxes $\left(707,1590\right.$ and $\left.2688 \mathrm{~kg} \mathrm{~m}^{-2} \mathrm{~s}^{-1}\right)$ and three heat fluxes $\left(8.2,14.8\right.$ and $\left.18.5 \mathrm{~kW} \mathrm{~m}^{-2}\right)$ were varied simultaneously in their experiments, while the pressure ranged from 1.5 to $20 \mathrm{bar}$ and the vapor qualities ranged from 0 to 0.6 . They compared their experimental data with the correlations by Mishra et al. [11], Bennett and Chen [29] and the pure fluid correlation by Jung et al. [2], and found that only the Mishra et al. [11] correlation with $[C, m, n]=[5.64,0.23,0.05]$ gave reasonable predictions (errors less than $12 \%$ ). Comparing these coefficients with those proposed by Rivera and Best [9] show remarkable inconsistencies (coefficients $C, m$ and $n$ are $91 \%, 54 \%$ and 67 $\%$ smaller than those of Rivera and Best [9]), however, the mass flux range in these experiments differs by more than two orders of magnitude.

These flow boiling experimental studies do not provide sufficient information for the development of a general in-tube flow-boiling correlation for the ammonia-water mixtures. Most importantly, the composition was barely varied and the reduced pressure was too low for high pressure Kalina cycles. The fact that the composition was barely varied favors simple boiling expressions such as the correlation by Mishra et al. [11]. 


\subsection{Pool boiling of ammonia-water mixtures}

Nucleate pool boiling correlations for mixtures are generally expressed as follows (see Table $31)$ :

$$
\frac{h}{h_{\mathrm{I}}}=\frac{\Delta T_{\mathrm{I}}}{\Delta T}=\frac{1}{1+K}
$$

4 where $h_{\mathrm{I}}$ and $T_{\mathrm{I}}$ denote the ideal heat transfer coefficient and ideal wall superheat, respectively, 5 and $K$ is a factor representing the heat transfer degradation. In general, it depends on the thermophysical and transport properties of the mixture, the liquid-vapor equilibrium relationship, the 7 slope of vapor pressure curve and the non-linear dependence on composition. The latter may be incorporated by using either the vapor-liquid composition difference $|\tilde{y}-\tilde{x}|$ or the boiling range $\left(\Delta T_{\mathrm{bp}}=T_{\mathrm{dew}}-T_{\mathrm{bub}}\right)$. The ideal wall superheat $\Delta T_{\mathrm{I}}$ is typically based on the molar average of the pure fluid wall superheats, i.e. the linear molar mixing law:

$$
\Delta T_{\mathrm{I}}=\sum_{j=1}^{N} \tilde{x}_{j} \Delta T_{j}=\frac{q}{h_{\mathrm{I}}}
$$

for which a division by the heat flux $q$ leads to

$$
\frac{1}{h_{\mathrm{I}}}=\sum_{j=1}^{N} \frac{\tilde{x}_{j}}{h_{j}}
$$

Here an appropriate pure fluid pool boiling correlation is used to predict the pure fluid nucleate boiling heat transfer coefficients. Alternatively, $h_{\mathrm{I}}$ may be evaluated using mixture properties directly in the pure fluid correlation. Equation 7 seems to be applied mostly in the open literature, however if boiling occurs in between each pure fluid critical pressures or in between each triple point pressures, Equation 7 fails, whereas the alternative method is generally applicable. Additionally, for multi-component mixtures, the evaluation of each component boiling coefficients becomes cumbersome.

Inoue et al. [42] were found to be the first researchers to conduct pool boiling experiments with ammonia-water mixtures. They employed a horizontal heated platinum wire $(d=0.3 \mathrm{~mm})$ and measured heat transfer coefficients over all ranges of composition, below heat fluxes of $2000 \mathrm{~kW} \mathrm{~m}^{-2}$ and at pressures of 4 and 7 bar, respectively. The results showed a remarkable decrease in the heat 
Table 1: Existing nucleate pool boiling correlations for mixtures

\begin{tabular}{|c|c|c|}
\hline Author & Correlation (generally applied) & \\
\hline Stephan and Körner [30] & $\frac{h}{h_{\mathrm{I}}}=\left\{1+A_{0}|\tilde{y}-\tilde{x}|(0.88+0.12 p[\mathrm{bar}])\right\}^{-1}, A_{0}=1.53$ & (8) \\
\hline Calus and Rice [31] & $\frac{h}{h_{\mathrm{I}}}=\left\{\left[1+|y-x|\left(\frac{\alpha_{\mathrm{L}}}{D_{\mathrm{L}}}\right)^{0.5}\right]^{0.7}\right\}^{-1}$ & (9) \\
\hline Jungnickel et al. [32] & $\frac{h}{h_{\mathrm{I}}}=\left\{1+K_{\mathrm{o}}|\tilde{y}-\tilde{x}|\left(\rho_{\mathrm{V}} / \rho_{\mathrm{L}}\right) q^{\left(0.48+0.1 \tilde{x}_{1}\right)}\right\}^{-1}$ & $(10)$ \\
\hline Schlünder [33] & $\frac{h}{h_{\mathrm{I}}}=\left\{1+\frac{h_{\mathrm{I}}}{q}\left(T_{s 2}-T_{s 1}\right)\left(\tilde{y}_{1}-\tilde{x}_{1}\right)\left[1-\exp \left(\frac{-B_{0} q}{\rho_{\mathrm{L}} h_{\mathrm{LV}} \beta_{\mathrm{L}}}\right)\right]\right\}^{-1}, B_{0}=1, \beta_{\mathrm{L}}=0.0002$ & (11) \\
\hline Thome and Shakir [25] & $\frac{h}{h_{\mathrm{I}}}=\left\{1+\frac{h_{\mathrm{I}}}{q} \Delta T_{\mathrm{bp}}\left[1-\exp \left(\frac{-B_{0} q}{\rho_{\mathrm{L}} h_{\mathrm{LV}} \beta_{\mathrm{L}}}\right)\right]\right\}^{-1}, B_{0}=1, \beta_{\mathrm{L}}=0.0003$ & (12) \\
\hline Fujita and Tsutsui [34] & $\frac{h}{h_{\mathrm{I}}}=\left\{1+\frac{\Delta T_{\mathrm{bp}}}{\Delta T_{\mathrm{I}}}\left[1-0.8 \exp \left(-\frac{q}{10^{5}}\right)\right]\right\}^{-1}$ & (13) \\
\hline Fujita and Tsutsui [35] & $\frac{h}{h_{\mathrm{I}}}=\left\{1+\frac{\Delta T_{\mathrm{bp}}}{\Delta T_{\mathrm{I}}}\left[1-\exp \left(\frac{-60 q}{\rho_{\mathrm{V}} h_{\mathrm{LV}}}\left\{\frac{\rho_{\mathrm{V}}^{2}}{\sigma g\left(\rho_{\mathrm{L}}-\rho_{\mathrm{V}}\right)}\right\}^{1 / 4}\right)\right]\right\}^{-1}$ & (14) \\
\hline Inoue et al. [36] & $\frac{h}{h_{\mathrm{I}}}=\left\{1+\frac{k \Delta T_{\mathrm{bp}}}{\Delta T_{\mathrm{I}}}\right\}^{-1}, k=\left[1-0.75 \exp \left(-\frac{0.75 q}{10^{5}}\right)\right]$ & (15) \\
\hline Vinayak Rao and Balakrishnan [37] & $\frac{h}{h_{\mathrm{I}}}=\left[1-\left(|\tilde{y}-\tilde{x}| \sqrt{\frac{D_{\mathrm{L}}}{\alpha_{\mathrm{L}}}}\right)^{0.5}\right]$ & (16) \\
\hline Author & Correlation (ammonia-water specific) & \\
\hline Arima et al. [38] & $\frac{h}{h_{\mathrm{I}}}=\left\{1+A_{1} \frac{k \Delta T_{\mathrm{bp}}}{\Delta T_{\mathrm{I}}}+A_{2}|\tilde{y}-\tilde{x}|(0.88+0.12 p[\mathrm{bar}])\right\}^{-1} A_{1}=0.134, A_{2}=2.07$ & (17) \\
\hline Táboas et al. [39] & $\frac{h}{h_{\mathrm{I}}}=\left\{1+\frac{x}{2} \frac{\left(T_{s 2}-T_{s 1}\right)\left(\tilde{y}_{1}-\tilde{x}_{1}\right)}{\Delta T_{\mathrm{I}}}\left[1-\exp \left(\frac{-B_{0} q}{\rho_{\mathrm{L}} h_{\mathrm{LV}} \beta_{\mathrm{L}}}\right)\right]+\frac{(1-x)}{2} \frac{\Delta T_{\mathrm{bp}}}{\Delta T_{\mathrm{I}}}\left[1-\exp \left(\frac{-B_{0} q}{\rho_{\mathrm{L}} h_{\mathrm{LV}} \beta_{\mathrm{L}}}\right)\right]\right\}^{-1}$ & (18) \\
\hline Inoue and Monde [40] & $\frac{h}{h_{\mathrm{I}}}=\left\{1+A_{1} \frac{k \Delta T_{\mathrm{bp}}}{\Delta T_{\mathrm{I}}}+A_{2} A_{0}|\tilde{y}-\tilde{x}|(0.88+0.12 p[\mathrm{bar}])\right\}^{-1}, A_{0}=3.10, A_{1}=0.15, A_{2}=0.65$ & (19) \\
\hline & $\frac{h}{h_{\mathrm{I}}}=\left\{1+A_{1} \frac{k \Delta T_{\mathrm{bp}}}{\Delta T_{\mathrm{I}}}+A_{3} \frac{\left(T_{s 2}-T_{s 1}\right)\left(\tilde{y}_{1}-\tilde{x}_{1}\right)}{\Delta T_{\mathrm{I}}}\left[1-\exp \left(\frac{-B_{0} q}{\rho_{\mathrm{L}} h_{\mathrm{LV}} \beta_{\mathrm{L}}}\right)\right]\right\}^{-1}, A_{1}=0.15, A_{3}=0.25$ & (20) \\
\hline Sathyabhama and Babu [41] & $\frac{h}{h_{\mathrm{I}}}=\left\{\left[1+|y-x|\left(\frac{\alpha_{\mathrm{L}}}{D_{\mathrm{L}}}\right)^{0.5}\right]^{0.67}\right\}^{-1}$ & (21) \\
\hline
\end{tabular}

1 transfer performance of the mixture close to the pure components. Five nucleate pool boiling mix2 ture correlations (Equation 8, 10, 11, 13 and 15) were compared to their experimental data, but 3 all of them failed to predict the measured coefficients satisfactory. Inoue et al. [42] noted that the 4 non-linear variation in the heat transfer coefficient with composition was different than the non5 linear variation of both $|\tilde{y}-\tilde{x}|$ and $\Delta T_{\mathrm{bp}}$ with composition, which is typically in contrast to other 
fluid mixtures. No alternative correlation was proposed by the authors.

Arima et al. [38] investigated pool boiling of ammonia-water mixtures on a horizontal flat heated silver surface at both low pressure and low ammonia mass fraction $(2,4$ and 7 bar; $0<x<$ $0.27)$ and high pressure and high ammonia mass fraction (7, 10 and 15 bar, $0.5<x<1)$. The splitting of concentration range and pressures resulted from their experimental apparatus' upper temperature limit of $160^{\circ} \mathrm{C}$. They compared their results with two correlations (Equation 8 and 15). Equation 8 uses $|\tilde{y}-\tilde{x}|$ to express the non-linear variation with concentration while Equation 15 uses $\Delta T_{\mathrm{bp}}$. Again, none of the correlations were found to give satisfactory predictions, however, Arima et al. [38] proposed a revised correlation (Equation 17) that essentially is a combination of Equation 8 and 15. No uncertainty measures of the new correlation were given. Additionally, the ideal heat transfer coefficient were computed by Equation 7 with modified constant and exponents in the Nishikawa and Fujita [43] pure fluid correlation.

Táboas et al. [39] used the experimental data obtained by Inoue et al. [42] and Arima et al. [38], for heat fluxes below $1 \mathrm{MW} \mathrm{m}^{-2}$ and compared those data with three correlations (Equation 11, 12 and 14). All these correlations under-predicted the experimental heat transfer coefficients. Equation 7 was used for the ideal heat transfer coefficient, where it was found that the Mostinski [44] correlation was the most adequate to predict both the pure water and ammonia pool boiling coefficients compared to others [45-47]. Finally, a new revised correlation (Equation 18) was proposed that is also a combination of two correlations, i.e. Equation 11 and 12. The correlation reproduces the experimental data well within a $40 \%$ accuracy range.

Inoue and Monde [40] later compared three correlations (Equation 8, 11 and 15) with their improved data collection and found that the combinations of Inoue et al. [36] with either the correlation by Stephan and Körner [30] or Schlünder [33] were able to predict $97 \%$ of their data within $20 \%$ accuracy below $1 \mathrm{MW} \mathrm{m}^{-2}$ at 4 bar (Equation 19 and 20). Again, Equation 7 was used where the pure component pool boiling coefficients were obtained by the most recent Nishikawa and Fujita [48] correlation with original coefficients except for the nucleation factor (0.39) for ammonia.

Sathyabhama and Babu [41] investigated pool boiling of ammonia-water on a cylindrical stainless steel $\operatorname{rod}(d=6 \mathrm{~mm})$. The experiments were performed at heat fluxes from 360 to 
$2000 \mathrm{~kW} \mathrm{~m}^{-2}$, ammonia mass fractions from 0 to 0.3 and pressures of 4,6 , and 8 bar. They compared seven different existing correlations (Equation 8, 9, 11, 14, 16, 19 and 20) with their measurements and found that the correlations (Equation 8,9 and 20) predicted their data within 20 $\%$ accuracy. They further modified the exponent in the Calus and Rice [31] correlation (Equation 21), and compared it to the experimental data from Arima et al. [38] and Inoue and Monde [40]. The modified Calus and Rice [31] correlation was found to predict most of this literature data within $40 \%$ limit for all ranges of mass fraction. Interestingly, this correlation has no dependency on the heat flux. Sathyabhama and Babu [41] compared several pure fluid pool boiling correlations for water, and found that the correlations by Stephan and Abdelsalam [45] and Nishikawa et al. [49] gave reasonable results. An earlier study by the same research group [50] acknowledged the Mostinski [44] correlation amongst others for ammonia, however, no exact indication of how to calculate the ideal heat transfer coefficient was given.

\subsubsection{Comparison of pool boiling correlations}

From the above literature survey, it may be concluded that most authors use a combination of correlations that use either the concentration difference $|\tilde{y}-\tilde{x}|$ or the boiling range $\Delta T_{\mathrm{bp}}$, respectively, to correlate their experimental data. Only the proposed correlation by Sathyabhama and Babu [41] (Equation 21) uses $|\tilde{y}-\tilde{x}|$ solely to express the reduction in the nucleate pool boiling, however, this correlation relies on transport properties of ammonia-water mixtures (thermal diffusivity and mass diffusivity), which are not well established in the open literature. Additionally, the survey shows that correlations in terms of concentration difference best represent the experimental data trend at low ammonia concentration, while correlations in terms of boiling range best represent the experimental data trend at high concentration.

All of the aforementioned pool boiling correlations use Equation 7 to compute the ideal heat transfer coefficient. In order to understand the effects of using different pure fluid pool boiling correlations at higher pressures, several well-known correlations for both fluids are evaluated in Figure 1. These correlations are the most recent by Nishikawa and Fujita [48] (with a nucleation factor of 0.39 for ammonia), the modified Nishikawa and Fujita [43] correlation by Arima et al. [12], the Nishikawa et al. [49] version used by Sathyabhama and Babu [41], and the correlations by 

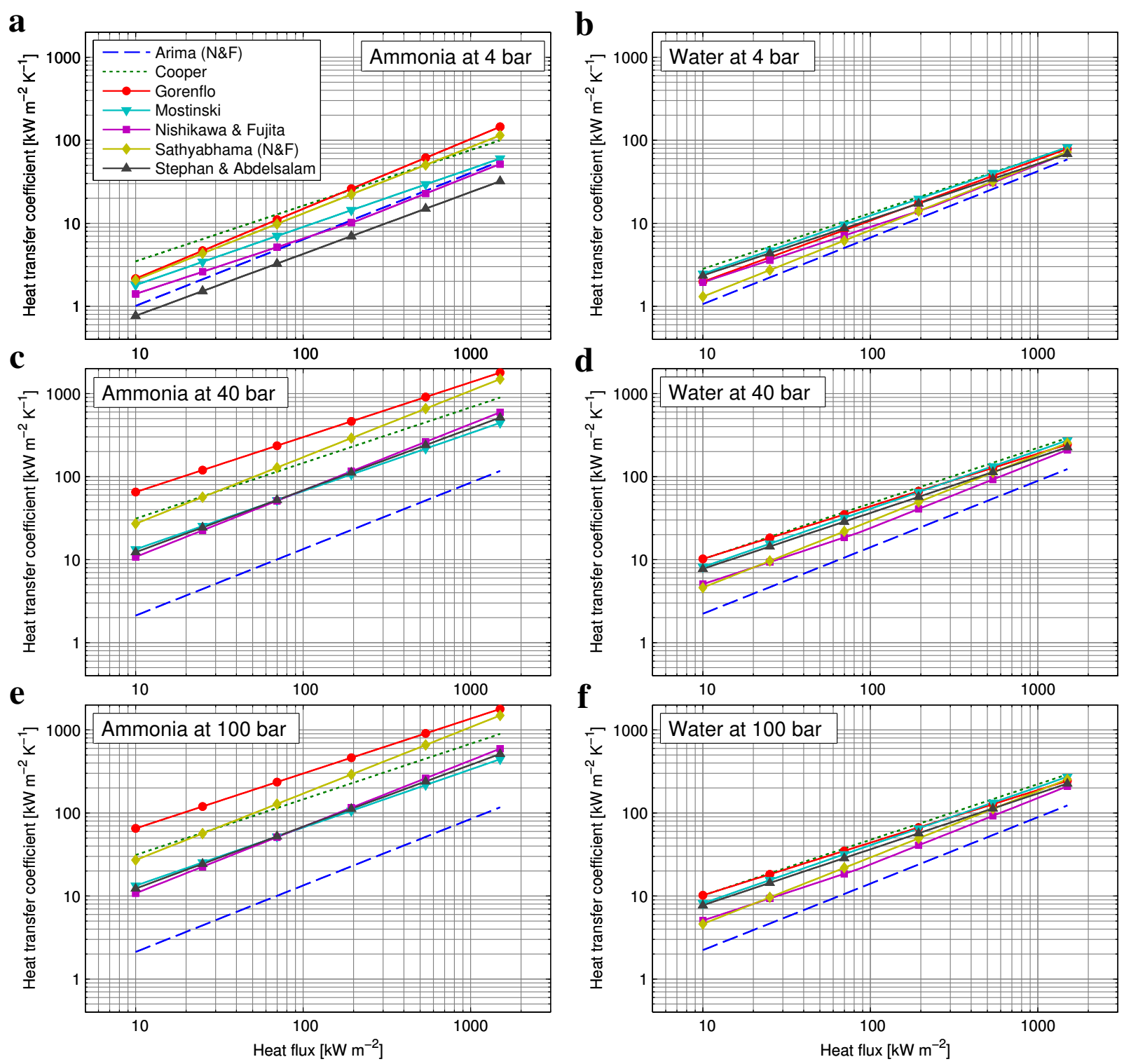

Figure 1: Pure ammonia and water pool boiling predictions as function of heat flux at different pressures

1 Cooper [46], Gorenflo and Kenning [47], Mostinski [44] and Stephan and Abdelsalam [45]. The 2 equation developed for refrigerants was used for ammonia in the Stephan and Abdelsalam [45]

3 correlation. Also the influence of surface roughness was neglected in the correlations by Cooper 4 [46] and Gorenflo and Kenning [47].

5 The results indicate that the pool boiling correlations tend to differ more dramatically for am6 monia than for water at higher pressures, thus different pressure dependencies are estimated by the 
a

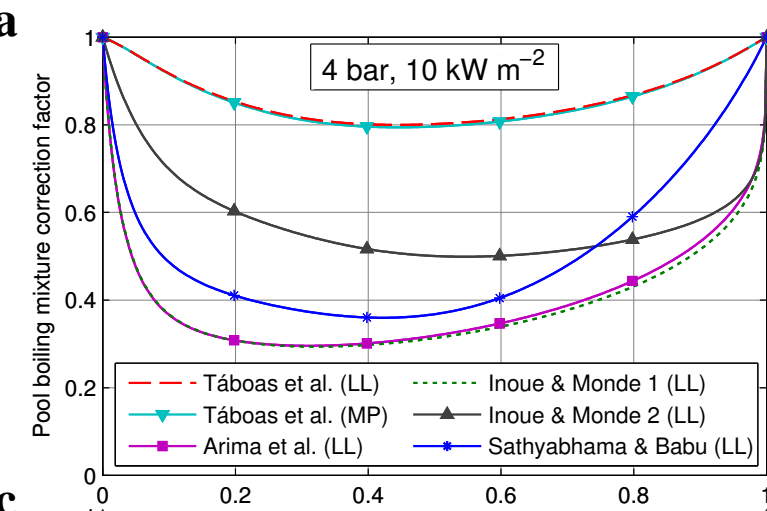

C

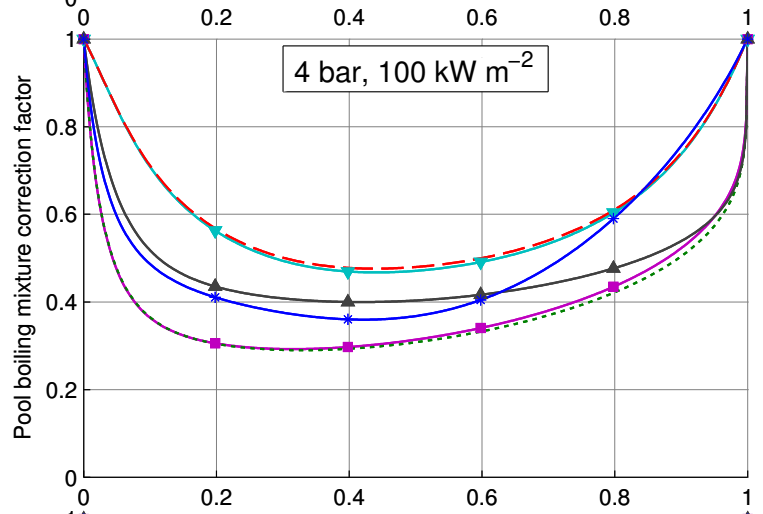

e

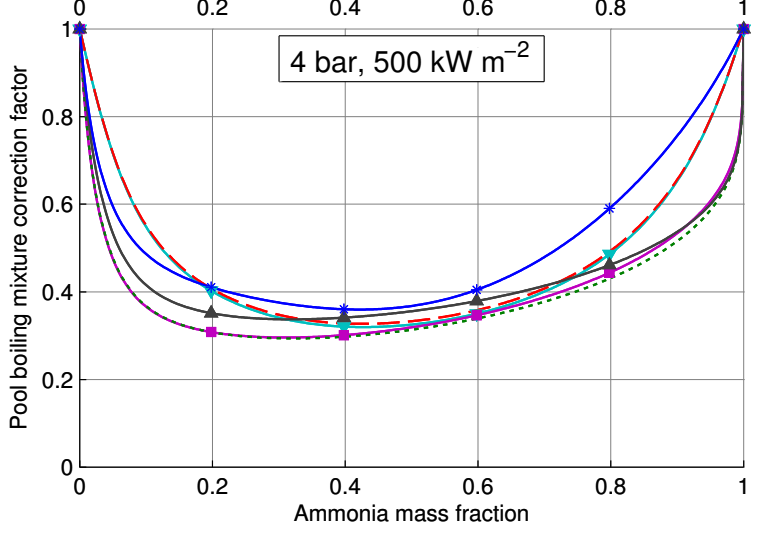

b

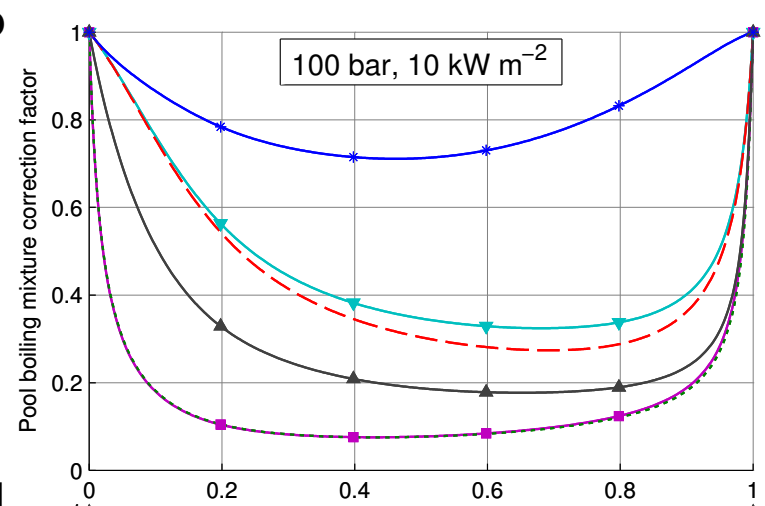

d

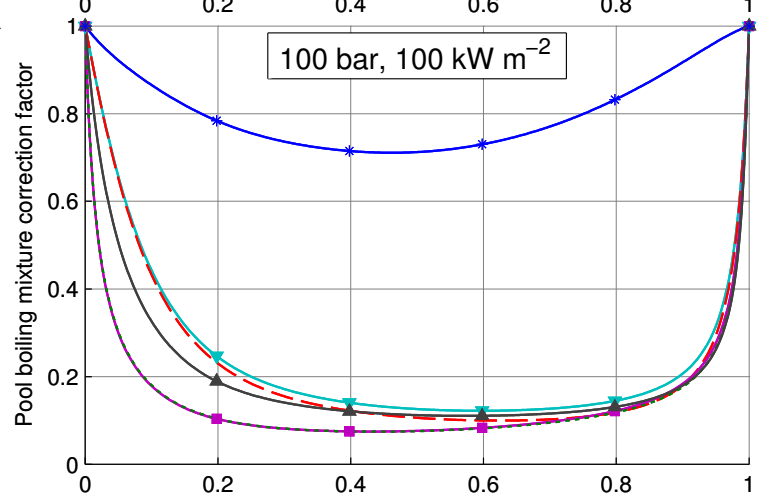

f

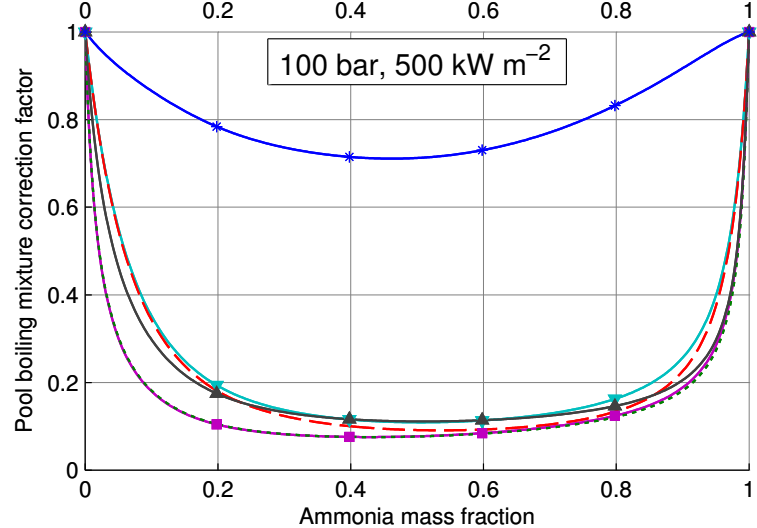

Figure 2: Pool boiling mixture correction factors (correlations) as function of ammonia mass fraction at various pressures and heat fluxes; (LL) is using the linear law (Equation 7) with the Mostinski [44] correlation; (MP) is using the Mostinski [44] correlation directly with mixture properties to evaluate $h_{I}$

1 correlations for the pure ammonia. Táboas et al. [39] also compared a set of pool boiling correla-

2 tions for ammonia to the available experimental data sets in the literature. They found relatively

3 large discrepancies among the various experimental data sets, and noted that some correlations

4 were developed from only some of the data sets, thus giving rise to discrepancies in the correla- 
tions also. Furthermore, only 11 data points from the same data set goes beyond 15 bar. For these reasons, one must be careful when selecting a pool boiling correlation for ammonia.

Following the recommendations by Táboas et al. [39], Inoue and Monde [40] and Sathyabhama and Hegde [50], the pool boiling of ammonia may be satisfactorily predicted by the correlations of Mostinski [44], Stephan and Abdelsalam [45] and the most recent correlation by Nishikawa and Fujita [48] with a nucleation factor of 0.39 at low pressures. These correlations tend to coincide at higher pressures also. The correlation by Mostinski [44] is rather simple and it has also been recommended by Táboas et al. [39] for water. For these reasons, the correlation by Mostinski [44] was used for both the pure ammonia and water pool boiling predictions in the current work.

Figure 2 depicts the pool boiling mixture correction factor $\left(F_{c}=h / h_{I}\right)$ using Equation 17 to 21 from Table 1.

In addition to the linear law (LL) (Equation 7), an example is included (Táboas et al. (MP)) for which the mixture properties (MP) have been used directly in the pool boiling correlation by Mostinski [44] to compute the ideal heat transfer coefficient. It is observed that the significance in the computation of the ideal heat transfer coefficient is small even at high pressure (Táboas et al. (MP) vs. Táboas et al. (LL)).

The general trend in Figure 2 is that the pool boiling mixture correction factor decreases (mass transfer resistance increase) as either pressure or heat flux increases. It is well known that the pool boiling heat transfer coefficient increases with both pressure and heat flux, thus causing the mass transfer resistance to increase. On the other hand, if the heat transfer coefficient tends to zero, so does the heat flux and the mixture correction factor must tend to unity. This dependency is in fact a property of most of the correlations presented in Table 1. The correlations by Arima et al. [38] and Inoue and Monde [40] (Equation 17 and 19) are however weak functions of heat flux compared to the correlations by Táboas et al. [39] and Inoue and Monde [40] (Equation 18 and 20), whereas the correlation by Sathyabhama and Babu [41] (Equation 21) is not a function of the heat flux. The differences in the predicted pool boiling mixture correction factor tend to be larger at low heat flux and smaller at high heat flux, excluding the correlation by Sathyabhama and Babu [41] which show a much different result at high pressures. Relatively large reductions in the pool boiling predictions are possible with respect to the ideal value, i.e. up to $70 \%$ at 4 bar and $90 \%$ 
1 at 100 bar.

\section{2.3. Pool boiling extensions to flow boiling}

$3 \quad$ Following the approach by Palen [16] and Thome [17, 51], the general pure fluid flow boiling 4 correlations may be modified in the nucleate boiling contribution to flow boiling by using the pool 5 boiling mixture correction factor $\left(F_{\mathrm{c}}=h / h_{\mathrm{I}}\right)$ defined in the previous section.

$6 \quad$ Palen [16] modified the widely quoted Chen [52] correlation to include the mixture boiling 7 correction factor by Palen and Small [53] and obtained

$$
h=h_{\mathrm{L}} F+h_{\mathrm{nb}} S F_{\mathrm{c}}
$$

where $F$ is the two-phase multiplier, $h_{\mathrm{nb}}$ is the nucleate boiling coefficient, $S$ is the boiling suppression factor and $F_{\mathrm{c}}$ is given as

$$
F_{\mathrm{c}}=\exp \left(-0.027 \Delta T_{\mathrm{bp}}\right)
$$

8 with a minimum value such that $F_{\mathrm{c}} \geq 0.1$. The other parameters are computed using the same 9 equations as in the original Chen [52] correlation using mixture properties.

Thome [51] provided another modification of the Chen [52] correlation by using Equation 12 1 for $F_{c}$ in Equation 22. In a later review on boiling of new refrigerants, Thome [17] showed how to 12 apply the same modification in the Chen-type correlation by Gungor and Winterton [1]

$$
h=h_{\mathrm{L}} E_{0}+h_{\mathrm{nb}} S F_{\mathrm{c}}
$$

where $E_{0}$ is the convective enhancement factor analogous to the two-phase multiplier $F$ in Equation 22. Again all parameters except $F_{\mathrm{c}}$ are evaluated by the original Gungor and Winterton [1] correlation with mixture properties. Similarly, the simplified Gungor and Winterton [26] correlation was modified for mixtures as

$$
\begin{gathered}
h=h_{\mathrm{L}} E \\
E=1+3000\left(\mathrm{Bo} F_{\mathrm{c}}\right)^{0.86}+1.12\left(\frac{X}{1-X}\right)^{0.75}\left(\frac{\rho_{\mathrm{L}}}{\rho_{\mathrm{V}}}\right)^{0.41}
\end{gathered}
$$


1 The heat flux to use for evaluating the mixture boiling correction factor, $F_{\mathrm{c}}$, is the nucleate boiling 2 heat flux and not the total heat flux as pointed out by Thome [17]. The total heat flux may be used 3 as an approximation for small boiling range mixtures only, which does not apply for ammonia4 water mixtures.

\subsection{Classical wide-boiling correlations}

Grauso et al. [22] gathered many experimental studies on wide-boiling mixtures and defined 7 "wide-boiling mixtures" as mixtures with a boiling range of more than $5 \mathrm{~K}$. Most of the considered mixtures had a maximum boiling range of less than $30 \mathrm{~K}$, while that of the ammonia-water mixture is $94.5 \mathrm{~K}$ at 1 bar and $66.7 \mathrm{~K}$ at 100 bar. Only a single experimental study [54] was found in their literature survey with a fluid mixture (R22-DMAC) having a boiling range more than ammoniawater (over $200 \mathrm{~K}$ ). In this study, it was found that the nucleate boiling was suppressed and that the Chen [52] correlation with negligible nucleate boiling contribution was found to predict the experiments best. It may indicate that the nucleate boiling is much suppressed for mixtures with very wide boiling range such as the ammonia-water mixture. On the other hand, Grauso et al. [22] compared their experimental results obtained for $\mathrm{CO}_{2}$-propane blends including the data banks by Wettermann and Steiner [15] and Cho et al. [55], and found that the correlation by Wettermann and Steiner [15] performed best and predicted $61 \%$ of the heat transfer coefficients within $30 \%$ error.

The correlation by Wettermann and Steiner [15] was specifically developed for mixtures with wide-boiling range (e.g. R116-R134a with maximum $\Delta T_{\mathrm{bp}}=28.6 \mathrm{~K}$ at $11 \mathrm{bar}$ ). It is also an extension of a well-known pure fluid flow boiling correlation by Steiner and Taborek [56], who used the asymptotic model to weight the nucleate and convective boiling contributions:

$$
h=\sqrt[3]{\left(F_{\mathrm{cb}} h_{\mathrm{cb}}\right)^{3}+\left(F_{\mathrm{nb}} h_{\mathrm{nb}}\right)^{3}}
$$

Wettermann and Steiner [15] employed the nucleate boiling correlation by Thome and Shakir [25] (Equation 12) with $h_{\mathrm{I}}$ defined by Equation 7 to compute the nucleate boiling heat transfer coefficient $h_{\mathrm{nb}}$. Note that $F_{\mathrm{nb}}$ is a nucleate boiling correction factor rather than a suppression factor, which is not needed in asymptotic models. Wettermann and Steiner [15] used $F_{\mathrm{nb}}=1$, 
where the other parameters were computed similarly to the original pure fluid correlation with mixture properties. Note that the correlation by Wettermann and Steiner [15] also involves the determination of a high boundary heat flux $q_{\mathrm{B}}$ and the onset of nucleate boiling $q_{\mathrm{onb}}$. When $q<q_{\mathrm{onb}}$ the nucleate boiling contribution is neglected, and when $q>q_{\mathrm{B}}$ the nucleate boiling contribution is calculated by means other than Equation 12 .

Another classical wide-boiling correlation is given by Jung et al. [2]. The correlation is also a Chen-type correlation and is given by:

$$
h=C_{\mathrm{me}} F h_{\mathrm{L}}+\frac{N}{C_{\mathrm{UN}}} h_{\mathrm{UN}}
$$

Here $C_{\mathrm{me}}$ considers the mass transfer resistance in the convective boiling region, $0.9<C_{\mathrm{me}} \leq$ $1, F$ is the enhancement factor, $N$ is the suppression factor while $C_{\mathrm{UN}}$ and $h_{\mathrm{UN}}$ are the inverse mixture correction factor $\left(1 / F_{\mathrm{c}}\right)$ and nucleate pool boiling heat transfer coefficient, respectively, as proposed by Ünal [57]. The ideal heat transfer coefficient is computed by Equation 7 with the Stephan and Abdelsalam [45] correlation.

\subsection{Choice of correlations}

Table 2 summarizes the ammonia-water flow boiling correlations that are chosen for further investigations regarding the influence on the heat exchanger size. Two ammonia-water specific flow boiling correlations are considered as introduced in Section 2.1, which both rely on the simple correlation by Mishra et al. [11] with different coefficients. Three ammonia-water specific pool boiling correlations extended to flow-boiling are considered using the pure fluid flow boiling correlation by Gungor and Winterton [1] as described in Sections 2.2 and 2.3. The ammonia-water specific pool boiling correlation by Sathyabhama and Babu [41] is excluded from this analysis, because it is independent of the heat flux and gives results very different from the others at high pressures. Furthermore, the first correlation by Inoue and Monde [40] (Equation 19) is also excluded, because it coincides with the correlation by Arima et al. [38]. Finally, two classical wide-boiling correlations are used as introduced in Section 2.4.

Figure 3 shows the predicted heat transfer coefficients using these correlations vs. the vapor quality at $50 \%$ bulk ammonia mass fraction, 4 bar, mass fluxes of 50,150 and $400 \mathrm{~kg} \mathrm{~m}^{-2} \mathrm{~s}^{-1}$ and 
Table 2: Ammonia-water flow boiling correlations chosen for further investigations in the current work

\begin{tabular}{|c|c|c|}
\hline Correlation & Proposed by & \\
\hline Mishra et al. [11], Equation 1 & Rivera and Best $[9]$ with $[C, m, n]=[65,0.5,0.15]$ & \\
\hline Mishra et al. [11], Equation 1 & Khir et al. $[10]$ with $[C, m, n]=[5.64,0.23,0.05]$ & \\
\hline \multicolumn{3}{|c|}{ Ammonia-water specific nucleate pool boiling correlations extended to flow boiling } \\
\hline Pool boiling mixture correction factor & Ideal heat transfer coefficient method & Flow boiling correlation \\
\hline Arima et al. [38], Equation 17 & Equation 7 with Mostinski [44] & Gungor and Winterton [1] \\
\hline Táboas et al. [39], Equation 18 & Equation 7 with Mostinski [44] & Gungor and Winterton [1] \\
\hline Inoue and Monde [40], Equation 20 & Equation 7 with Mostinski [44] & Gungor and Winterton [1] \\
\hline \multicolumn{3}{|l|}{ Classical wide-boiling correlations } \\
\hline \multicolumn{3}{|l|}{ Wettermann and Steiner [15] } \\
\hline Jung et al. [2] & & \\
\hline
\end{tabular}

heat fluxes of 10 and $100 \mathrm{~kW} \mathrm{~m}^{-2}$ for a vertical tube having an inner diameter of $34 \mathrm{~mm}$.

Figure 3 indicate that the ammonia-water specific flow boiling correlations by Rivera and Best [9] and Khir et al. [10] are around an order of magnitude different from each other. Compared to the other correlations, the one by Rivera and Best [9] over-predicts while the one by Khir et al. [10] under-predicts the heat transfer coefficients. The general trend in Figure 3 is that an increase in the mass flux and heat flux increases the heat transfer coefficient. However, for the more elaborate methods (the ammonia-water specific pool boiling extensions to flow boiling and the classical wide-boiling correlations) the dependency on heat flux becomes suppressed at high vapor qualities and mass fluxes. The convective contribution to flow boiling, as predicted by Gungor and Winterton [1], is also presented in Figure 3. Compared to the pool boiling correlation extensions to flow boiling, it shows that the nucleate boiling contribution is rather small and mostly present at small vapor qualities, low mass fluxes and high heat fluxes. In other words, the different pool boiling mixture correction factors (see Figure 2) do not matter much when they are used to predict flow boiling. The classical wide-boiling correlations by Wettermann and Steiner [15] and Jung et al. [2] predict reasonably similar results and are close to the pool boiling extensions to flow boiling in most conditions.

Figure 4 shows the predicted flow boiling heat transfer coefficients at 100 bar. Here the cor- 

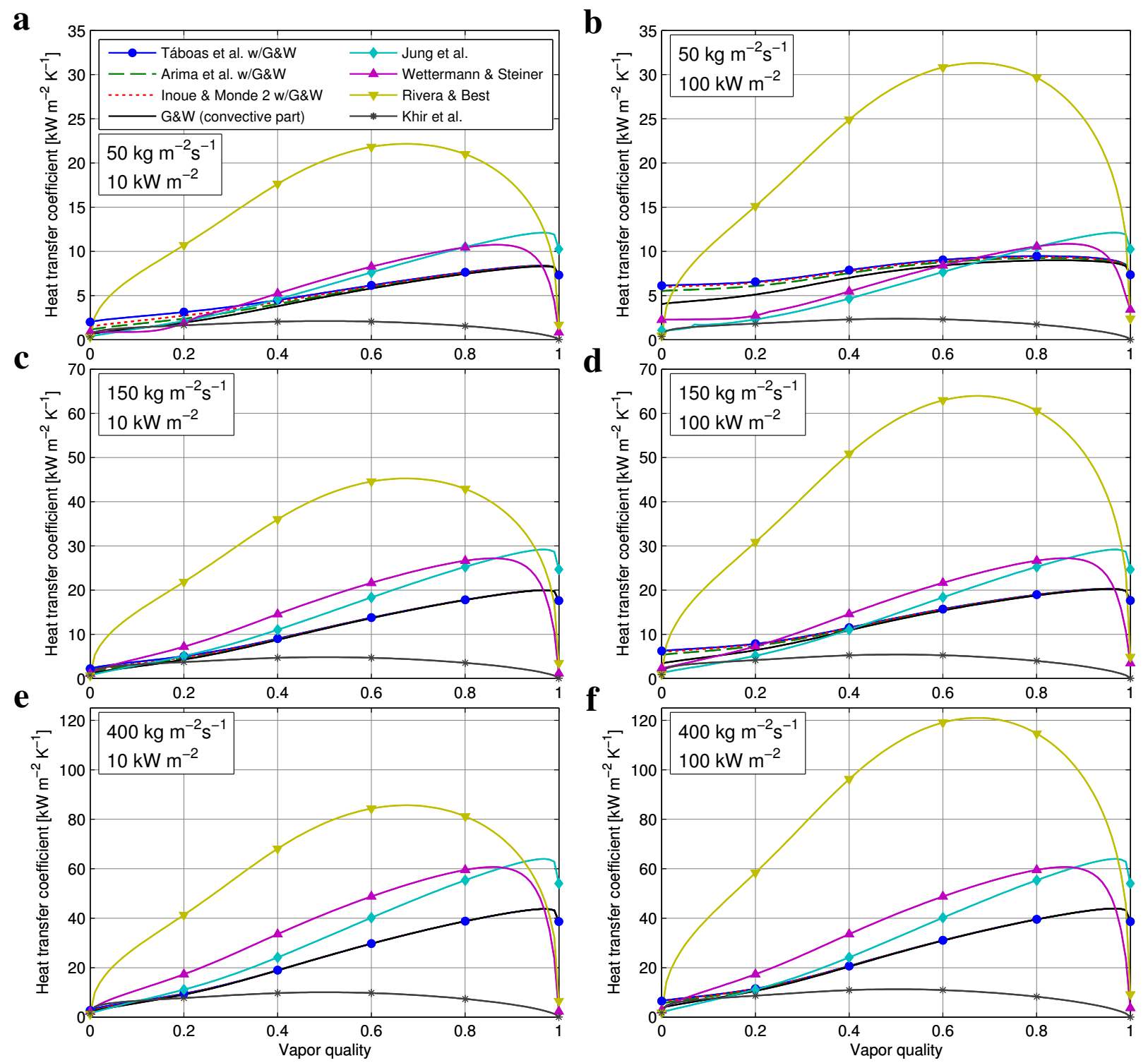

Figure 3: Flow boiling heat transfer predictions vs. vapor quality at $50 \%$ bulk ammonia mass fraction, 4 bar and various mass and heat fluxes; the tube is vertical and has an inner diameter of $34 \mathrm{~mm}$

1 relation by Rivera and Best [9] has been omitted in order to better visualize the rest, however, it 2 predicts the same order of magnitude higher than the Khir et al. [10] correlation, which is close to 3 the rest at 100 bar and low qualities. It seems that the pure fluid correlation by Gungor and Winter4 ton [1] gives erroneous predictions at both high pressure and high heat flux (see Figure 4b) when 5 compared with the classical wide-boiling correlations. Again the pool boiling extensions to flow 

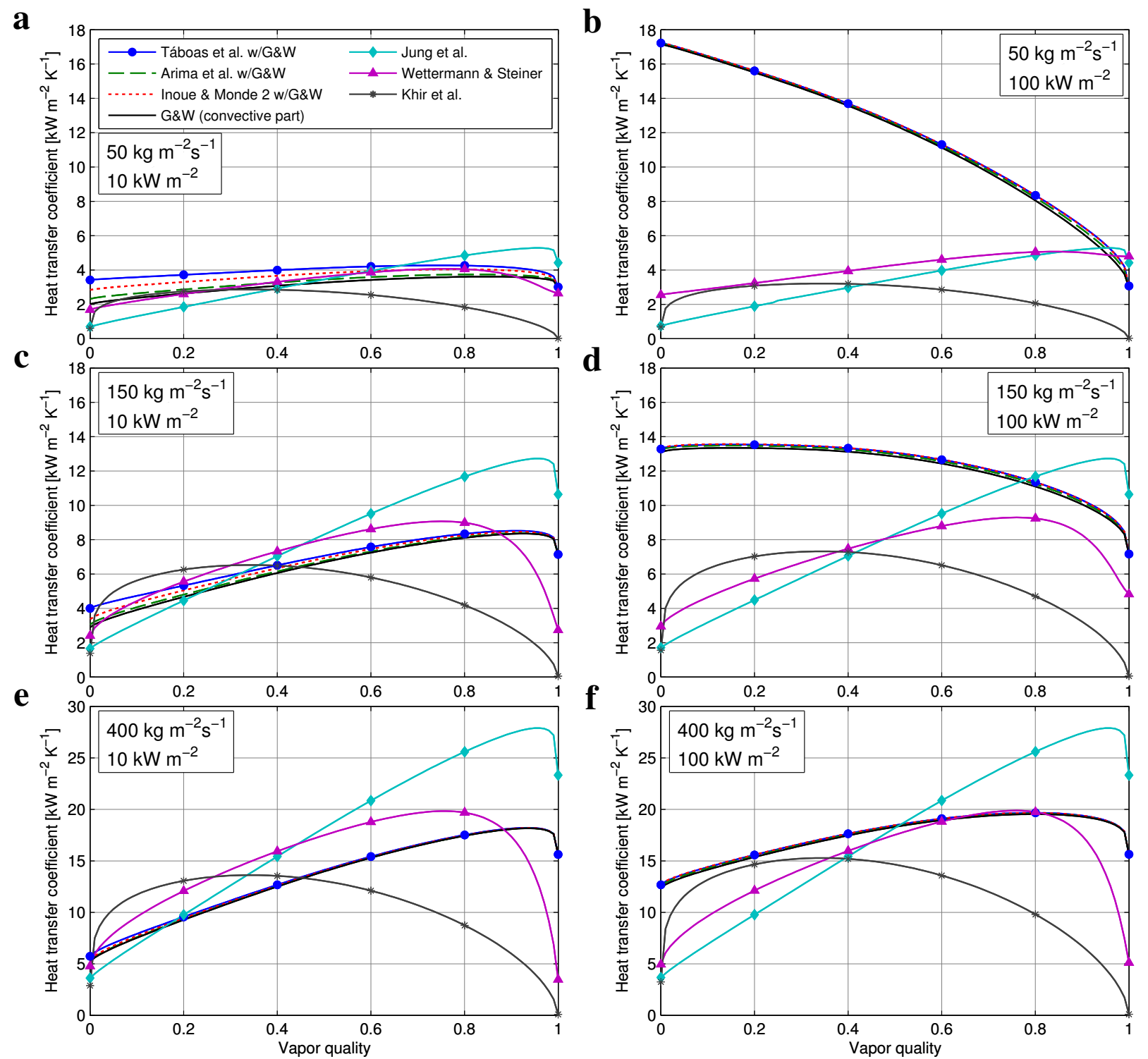

Figure 4: Flow boiling heat transfer predictions vs. vapor quality at $50 \%$ bulk ammonia mass fraction, 100 bar and various mass and heat fluxes; the tube is vertical and has an inner diameter of $34 \mathrm{~mm}$

1 boiling correlations indicate that the nucleate boiling contribution is small and mostly present at 2 low vapor qualities and mass fluxes. However, at both high pressure and high heat flux the nucle3 ate boiling is almost fully suppressed. The general trend as pressure increases is that the boiling 4 heat transfer coefficient decreases as compared with Figure 3. Again the classical wide-boiling 5 correlations give similar predictions and are close to the pool boiling extensions to flow boiling at 
most conditions.

\section{Model development}

This section presents the models of the flue gas based heat recovery boiler (HRB) for a combined cycle power plant and the oil based boiler (OBB) for a solar thermal power plant. The models represent Kalina cycle boilers with either poor or good heat transfer characteristics on the hot fluid side. The models are identical to the models used in Kærn et al. [8], except that the boiling heat transfer coefficients are computed differently. Note that the design of the boilers includes not only the evaporator, but also the economizer and the superheater. This is chosen so as to give a full overview of the boilers, i.e. how much the different boiling heat transfer correlations affects the evaporator area and the total area including the economizer and the superheater.

The thermodynamic properties of the ammonia-water mixture are evaluated using the NIST standardized reference database (REFPROP 9.12 [6]) for which the latest so-called "Ammonia (Lemmon)" fluid file is used for the ammonia-water mixture [58]. The fluid file contains a refit of the ammonia equation of state that is compatible with the latest excess Helmholtz mixture model. The new ammonia-water mixture formulation is more stable and faster while giving outputs that are very close to that of the earlier Tillner-Roth and Friend [5] formulation [59]. Additionally, the transport properties are evaluated with the formulations proposed by Conde-Petit [7]. The models are implemented in Dymola 2014 [60] using the Modelica language, for which the freely available Modelica-REFPROP interface [61] is used.

\subsection{HRB model}

A sketch of the HRB is shown in Figure 5 including the economizer (EC), the evaporator (EV) and the superheater (SH). The HRB is recognized as a once-through boiler having the cold fluid flowing inside a vertical tube bundle with external circular fins and the hot fluid flowing in a counter-cross flow arrangement. The hot fluid is simplified to be the product of a stoichiometric burning of methane and air $\left(21 \% \mathrm{O}_{2}, 79 \% \mathrm{~N}_{2}\right)$. The properties of the flue gas are evaluated using the Modelica.Media library, i.e. an ideal gas mixture. The inlet gas temperature and mass flow rate are $524^{\circ} \mathrm{C}$ and $100 \mathrm{~kg} \mathrm{~s}^{-1}$ replicating the exhaust gas conditions of a gas turbine. The 


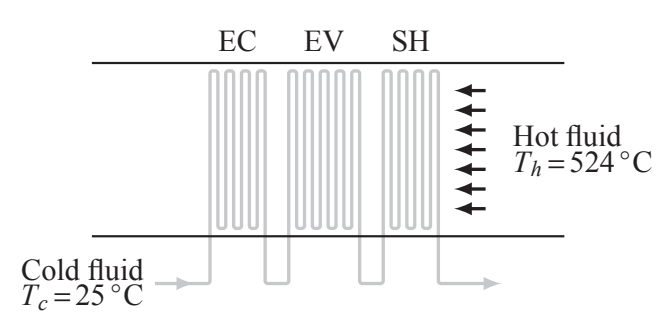

Figure 5: Heat recovery boiler

cold medium is the ammonia-water mixture with an ammonia mass fraction, inlet temperature and pressure of $0.7,25^{\circ} \mathrm{C}$ and $40 \mathrm{bar}$, respectively. The pinch point temperature difference is $15 \mathrm{~K}$ and the approach temperature difference (hot fluid inlet, cold fluid outlet) is $20 \mathrm{~K}$. The ammonia mass fraction and pressure are varied from 0.5 to 0.9 and 40-100 bar, respectively, which are typical inlet conditions in Kalina cycle boilers [18, 23, 24].

With these assumptions, for a given ammonia mass fraction, the temperature profiles of both fluids as function of the heat flow rate may be constructed, see Figure 7a. In other words, the heat exchange in the economizer, the evaporator and the superheater is known by these design conditions, while the heat exchanger surface area remains unknown.

The HRB model computes the local heat transfer by discretization with respect to the heat flow rate. The specific geometry of the HRB is listed in Table 3 and the applied heat transfer and pressure drop correlations other than the boiling heat transfer correlation are shown in Table 4. Additionally, the tube layout is staggered and the tube material is steel (constant thermal conductivity of $42 \mathrm{~W} \mathrm{~m}^{-1} \mathrm{~K}^{-1}$ is assumed).

The solution progress as well as a convergence analysis are described in Kærn et al. [8]. Based on the convergence analysis, the number of cells for the discretization is chosen to be 2000 .

\subsection{OBB model}

A sketch of the OBB is shown in Figure 6. The OBB is recognized as several shell and tube heat exchangers having 1 shell pass for the hot fluid and 1 tube pass for the cold fluid. The tubes have circular fins and no tubes are placed in the window section. These features serve to enhance the heat transfer on the oil side while maintaining a low pressure drop. The hot fluid is Therminol 
Table 3: Main geometry of the HRB

$\begin{array}{lr}\text { Tube length } & 5 \mathrm{~m} \\ \text { Inner tube diameter } & 34 \mathrm{~mm} \\ \text { Outer tube diameter } & 40.64 \mathrm{~mm} \\ \text { Fin density } & 236 \mathrm{~m}^{-1} \\ \text { Fin height } & 20 \mathrm{~mm} \\ \text { Fin thickness } & 1.5 \mathrm{~mm} \\ \text { Transverse tube pitch } & 100 \mathrm{~mm} \\ \text { Longitundinal tube pitch } & 90 \mathrm{~mm} \\ \text { Tubes per row / cold fluid circuits } & 60 \\ \text { Frontal area } & 30 \mathrm{~m}^{2} \\ \text { Minimum free flow area } & 13.56 \mathrm{~m}^{2}\end{array}$

Table 4: Heat transfer and pressure drop correlations

\begin{tabular}{|c|c|}
\hline \multicolumn{2}{|l|}{ Hot fluid } \\
\hline Heat transfer & Briggs and Young [62] \\
\hline Fin efficiency & Shah and Sekulic [63] ${ }^{a}$ \\
\hline Friction & Robinson and Briggs [64] \\
\hline \multicolumn{2}{|c|}{ Cold fluid single phase } \\
\hline Heat transfer & Gnielinski [65] \\
\hline Friction & Blasius [66] \\
\hline \multicolumn{2}{|c|}{ Cold fluid two-phase } \\
\hline Heat transfer & see Table 2 \\
\hline Friction & Müller-Steinhagen and Heck [67] \\
\hline
\end{tabular}

166 and the properties are obtained from Solutia Inc. [68]. The conditions are almost the same 2 as those of the HRB, except that the cold fluid and the hot fluid inlet temperatures are $50^{\circ} \mathrm{C}$ and $3320^{\circ} \mathrm{C}$, respectively. Again, the temperature profiles of both fluids as function of the heat flow rate 4 may be constructed (see Figure 7b), and the OBB remains to be designed to find the required heat 5 exchanger surface area.

6 The model of the OBB is identical to the HRB from previous section, except that the heat trans- 


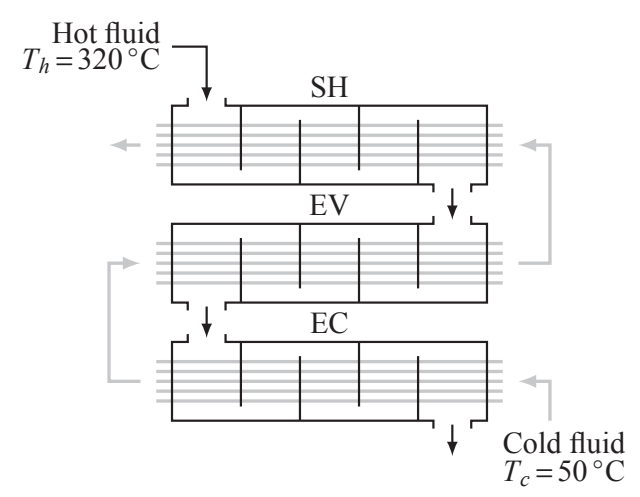

Figure 6: Oil based boiler

1 fer coefficient and pressure drop on the shell side are computed differently. The Bell-Delaware

method as extended by Taborek [69] has been used to establish the heat transfer coefficient and pressure drop on the shell side. In fact the ideal heat transfer coefficient and ideal pressure drop (ideal tube bundle cross flow through the centerline of the shell) are computed with the same correlations as for the HRB (Table 4), however corrected for non-ideal shell flow effects using the Bell-Delaware method. The entrance and exit baffle spacing effects have been neglected for simplicity. The specific geometry of the OBB is listed in Table 5. Additionally, the staggered rotated square layout is used and the tube material is steel.

Note that the number of parallel tubes has increased compared to the HRB from 60 to 120 . This was chosen in order to keep the shell length to diameter ratio reasonably low, thus reducing the resulting hot fluid flow length and corresponding pressure drop.

\section{Results}

In this section, the influence of the flow boiling heat transfer correlations on the predicted heat transfer surface area is reported for both the HRB and the OBB. The results are presented not only specific to the evaporator it-self, but also specific to the total boiler area, including the economizer and the superheater for completeness. Firstly, the results of a baseline numerical design at various pressures and ammonia mass fractions are presented for both the HRB and the OBB. This baseline serves as a reference to better understand the heat exchanger size differences when changing operation conditions and using the same flow boiling correlation. 
Table 5: Main geometry of the OBB

\begin{tabular}{lr} 
Number of parallel tubes & \multicolumn{1}{c}{120} \\
Inner tube diameter & $34 \mathrm{~mm}$ \\
Outer tube diameter & $40.64 \mathrm{~mm}$ \\
Fin density & $236 \mathrm{~m}^{-1}$ \\
Fin height & $10 \mathrm{~mm}$ \\
Fin thickness & $1 \mathrm{~mm}$ \\
Tube pitch & $70 \mathrm{~mm}$ \\
Shell bundle clearance & $15 \mathrm{~mm}$ \\
Shell inside diameter & $1014 \mathrm{~mm}$ \\
Central baffle spacing & $507 \mathrm{~mm}$ \\
Baffle cut ratio & 0.20 \\
Tube to baffle hole clearance & $0.8 \mathrm{~mm}$ \\
Shell to baffle hole clearance & $1.6 \mathrm{~mm}$ \\
\hline
\end{tabular}

\subsection{Baseline results}

4 Gungor and Winterton [1].

5

Table 6 shows a few baseline results at various pressures and ammonia mass fractions for both the HRB and the OBB, using the pool boiling extension to flow boiling with Táboas et al. [39] and

The heat rate varies from 40 to $57 \mathrm{MW}$ and is largest in the evaporator for both case studies, except that of the HRB at 100 bar and an ammonia mass fraction of 0.9. The heat transfer coefficient of the hot fluid is 6-7 times larger for the OBB compared to the HRB. It means that the heat transfer surface areas are approximately 5 times smaller for the OBB. The cold fluid pressure drop is higher for the HRB than the OBB, because the OBB has twice as many cold fluid circuits and shorter tubes. It also means that the cold fluid mass flux becomes approximately half of that of the HRB. The average heat flux in the evaporator varies from 46 to $66 \mathrm{~kW} \mathrm{~m}^{-2}$ and from 54 to 153 $\mathrm{kW} \mathrm{m}^{-2}$ for the HRB and the OBB, respectively.

Figure 7 shows the computed temperature profiles of the cold fluid, the hot fluid and the outer tube wall. Again, it indicates that the hot fluid gas-side controls the heat transfer process for the HRB, since the wall temperature is close to that of the cold fluid (Figure 7a). For the OBB (Figure $7 b)$, the wall temperature becomes closer to the average of the cold and the hot fluid throughout 
Table 6: HRB and OBB model results

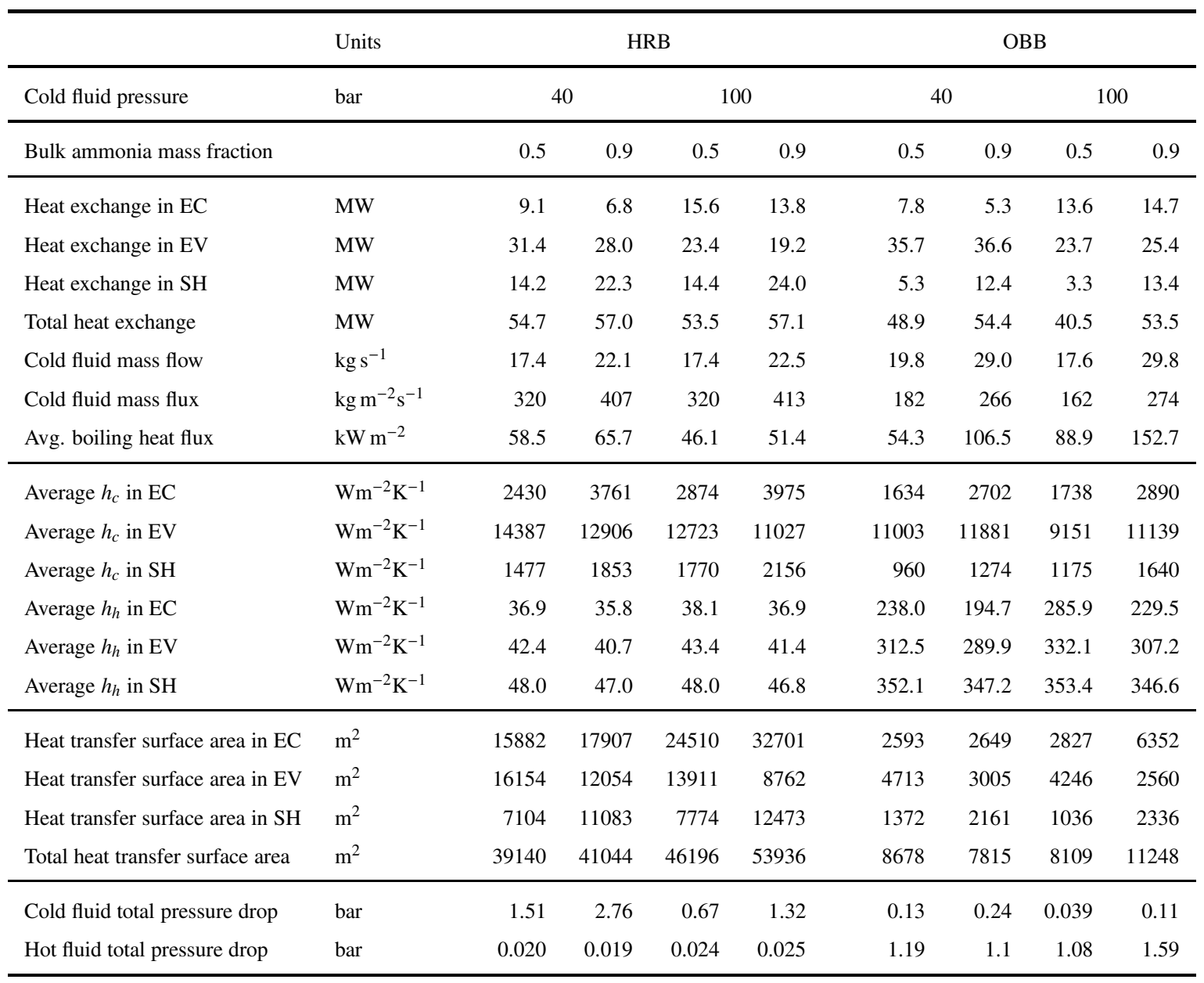

1 the heat exchanger, thus the heat transfer resistances of the hot and the cold fluids are more even.

Figure 8 presents the heat transfer surface area ratios of the economizer, the evaporator and the 3 superheater at 40 and 100 bar as function of the ammonia mass fraction. The results suggest that 4 the relative size of the evaporator is decreasing with increased ammonia mass fraction for both 5 the HRB and the OBB. Additionally, a higher pressure lowers the relative size of the evaporator. 6 The flow boiling correlations affects only the evaporator size and for that reason, the total boiler 7 area will not show as large area differences as the evaporator may for the different flow boiling 8 correlations. 

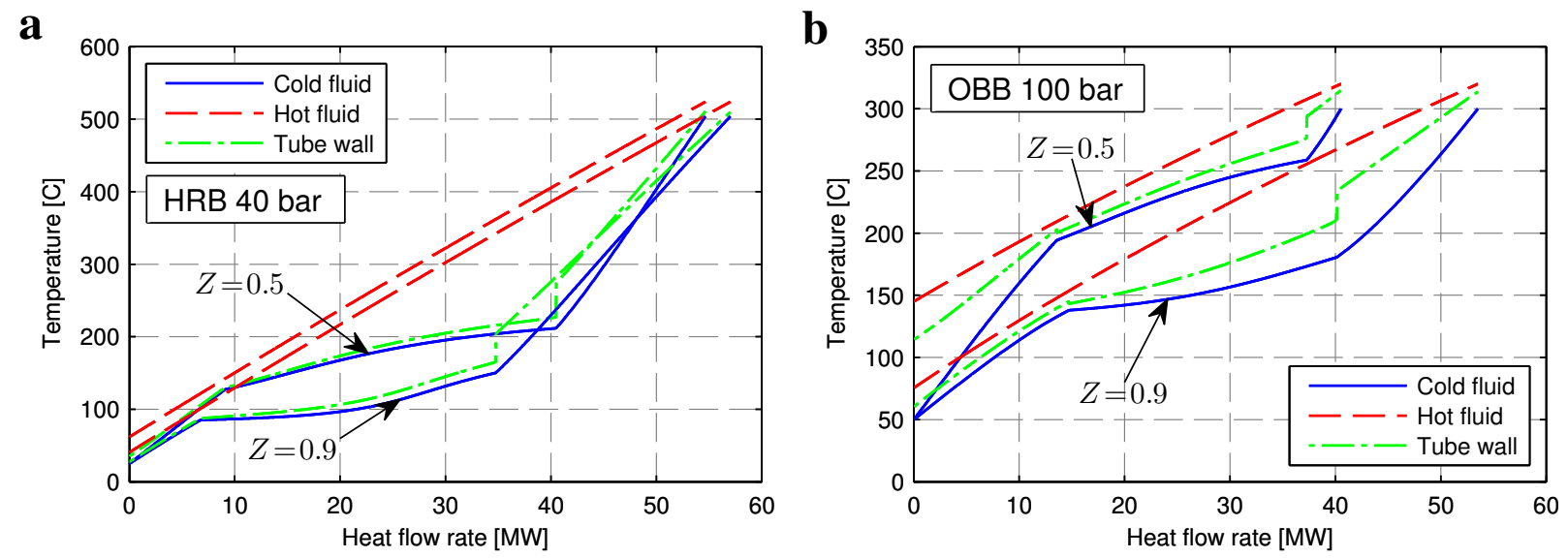

Figure 7: Temperature profiles vs. heat flow rate; (a) HRB at 40 bar and $Z=0.5,0.9$; (b) $\mathrm{OBB}$ at 100 bar and $Z=0.5,0.9$
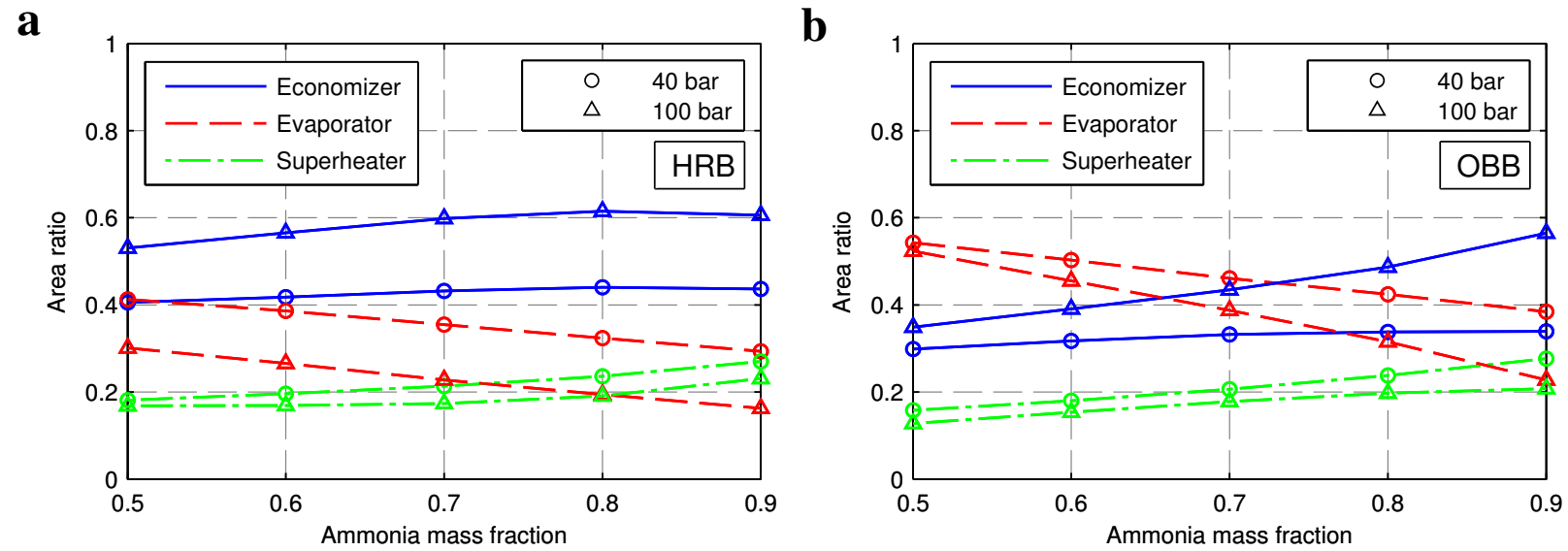

Figure 8: Area ratios of the economizer, the evaporator and the superheater vs. ammonia mass fraction; (a) HRB; (b) OBB

\subsection{Influence of different flow boiling correlations}

Figure 9 depicts the predicted evaporator areas for both the HRB and the OBB using the corre3 lations listed in Table 2, for which the areas are normalized by the average predicted area for each 4 conditions (each ammonia mass fraction and pressure).

The results indicate that the area differences are small for the HRB and larger for the OBB. The 6 difference between the highest and lowest predicted areas (maximum area difference) become $6 \%$ 7 and $28 \%$ for the HRB and the OBB, respectively. The trend with respect to the various correlations 


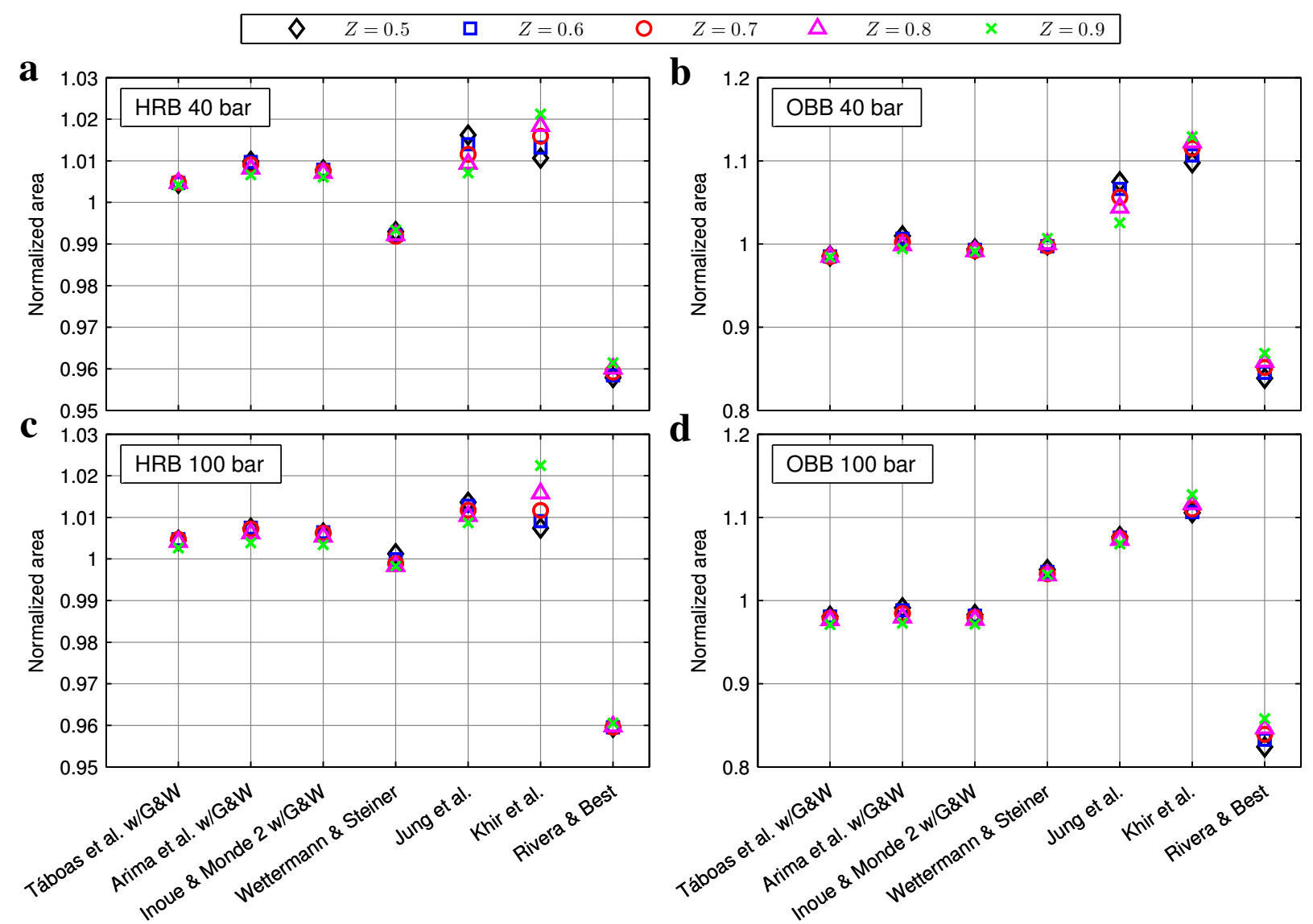

Figure 9: Predicted evaporator areas normalized by the average vs. the different flow boiling correlations (Table 2) for different pressures and ammonia mass fractions; HRB at 40 bar (a), OBB at 40 bar (b), HRB at 100 bar (c), OBB at 100 bar (d)

1 are similar for all ammonia mass fractions and pressures.

2 The results also suggest that the correlation by Rivera and Best [9] always gives the lowest 3 evaporator area, because of its relatively high predicted heat transfer coefficient (Figure 3). The 4 highest area is predicted mostly with the correlation by Khir et al. [10], because of its relatively 5 low heat transfer coefficient (Figure 3 and 4), however for the HRB the correlation by Jung et al. 6 [2] predicts the largest evaporator area at ammonia mass fractions of 0.5 and 0.6.

The influence of using the different flow boiling correlations on the total boiler area is presented 8 in Figure 10 for completeness. The predicted area differences for the total boiler become lower 9 than the evaporator and is related to the evaporator area ratio (Figure 8). The maximum area 


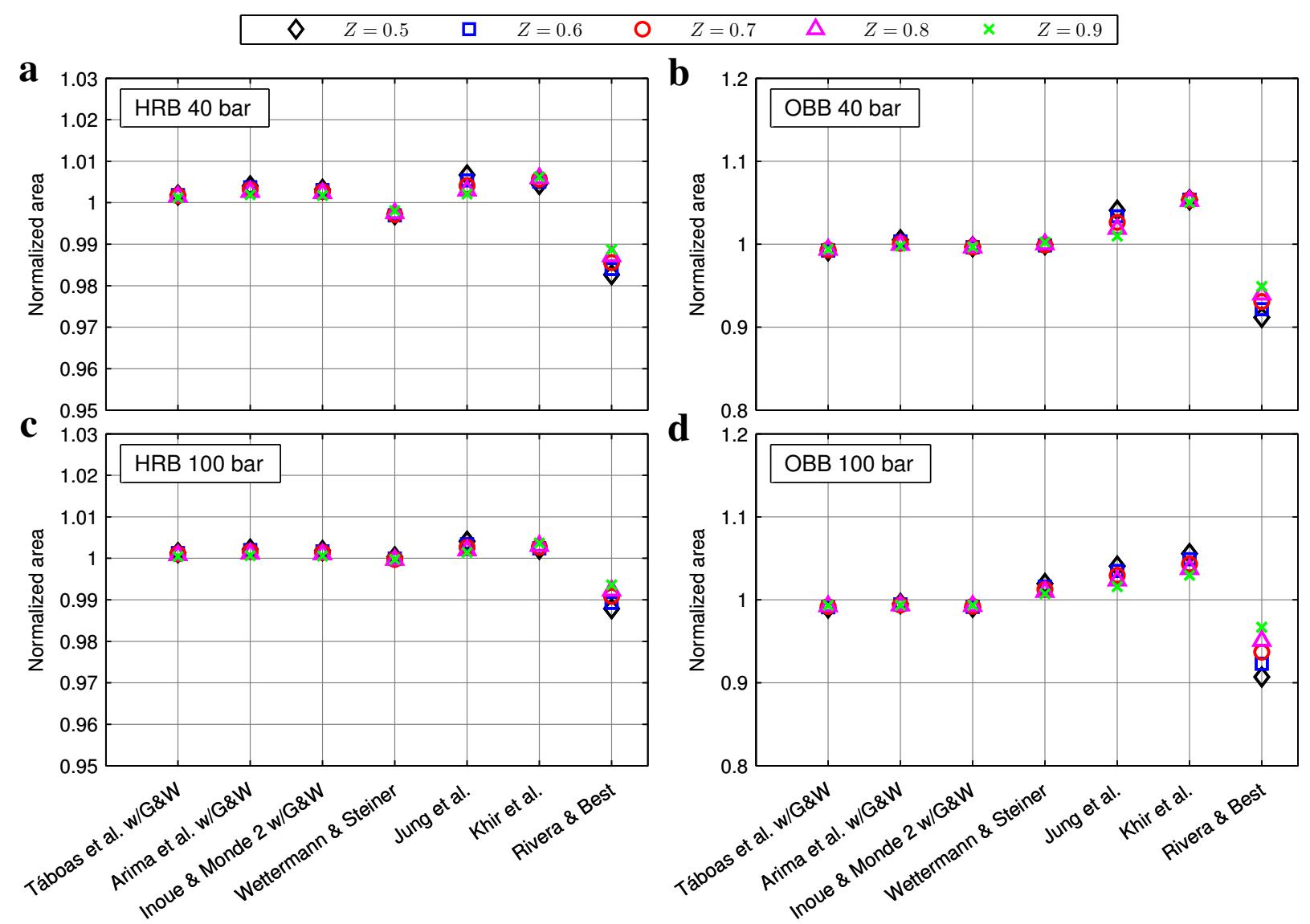

Figure 10: Predicted total boiler areas normalized by the average vs. the different flow boiling correlations (Table 2) for different pressures and ammonia mass fractions; (a) HRB at 40 bar; (b) OBB at 40 bar; (c) HRB at 100 bar; (d) OBB at 100 bar

1 difference become $2.5 \%$ and $14.9 \%$ for the HRB and the OBB, respectively. Otherwise, the trend 2 is similar to Figure 9.

3 For the HRB, the influence of the flow boiling correlations on the required heat transfer surface 4 area is weak during numerical design. However, for the OBB the choice of correlation have larger 5 influence (up to $28 \%$ for the evaporator). If the more elaborate correlations are used such as the 6 classical wide-boiling correlations or the ammonia-water specific pool boiling extensions to flow 7 boiling (excluding the results obtained using the simple correlations by Khir et al. [10] and Rivera 8 and Best [9]), then the maximum difference becomes less than $10 \%$ for the evaporator of the OBB 9 and less than $5 \%$ for the total OBB. 
$\mathbf{a}$

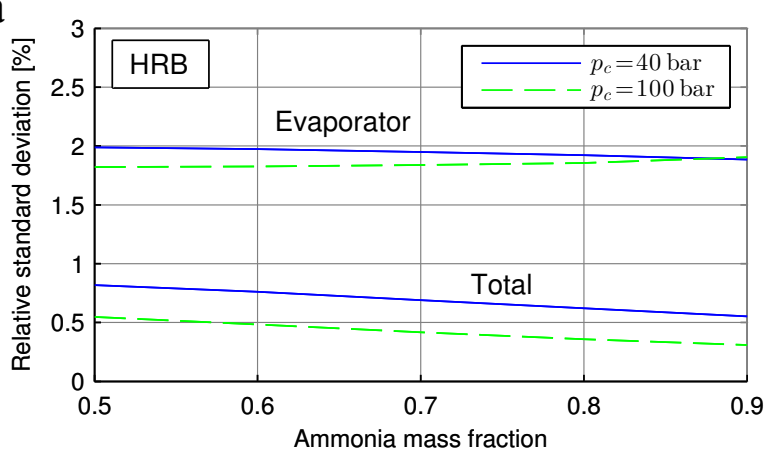

b

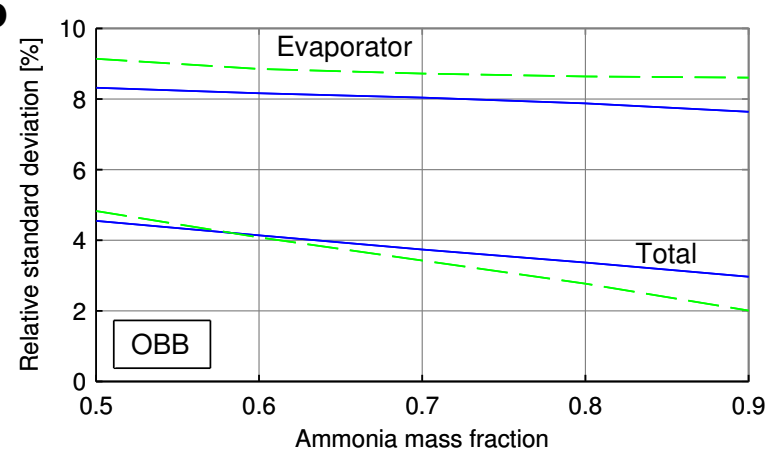

Figure 11: Relative standard deviation (RSD) of the predicted surface areas of the evaporator and the total boiler; $\operatorname{HRB}(\mathrm{a})$ and $\mathrm{OBB}(\mathrm{b}) . \mathrm{RSD}=\frac{1}{\bar{A}} \sqrt{\frac{1}{N-1} \sum_{i=1}^{N}\left(A_{i}-\bar{A}\right)^{2}}$

Figure 11a and $11 \mathrm{~b}$ indicate the relative standard deviation (RSD) of the predicted evaporator and total boiler areas. They confirm that the predicted area differences are insignificant for the HRB and small for the OBB when using the correlations listed in Table 2. Additionally, the relative standard deviations do not change significantly with either ammonia mass fraction or pressure. The highest relative standard deviation in the predicted evaporator area is $2 \%$ for the HRB and $9.1 \%$ for the OBB.

\section{Discussion}

The results indicate that the relatively large differences in the flow boiling heat transfer coefficients as presented in Figure 3 and 4 result in rather small evaporator size differences. The evaporator size differences are almost insignificant for the HRB. For the OBB, the evaporator size differences are less than the typical uncertainties related to the mixture flow boiling heat transfer correlations. These uncertainties may be as high as $40 \%$ and do not necessarily lead to the same uncertainty in the predicted heat transfer area. When excluding the simple Mishra et al. [11] type correlations, the evaporator area difference becomes below $10 \%$ for the OBB. The result is encouraging because it indicates that the use of different elaborate flow boiling correlations for the ammonia-water mixture have minor significance during heat exchanger design. 
The heat transfer correlations employed in the current work suggest that the nucleate boiling contribution to flow boiling is small compared to the convective contribution to flow boiling. Only at very low mass fluxes, low vapor qualities and high heat fluxes, the nucleate boiling contribution becomes significant for the ammonia-water mixture. For this reason, the different pool boiling mixture correction factors (Figure 2) do not matter much when they are used to predict the mixture flow boiling. In other words, the nucleate boiling is already rather suppressed by the presence of the flow at the current design conditions.

The convective contribution is well predicted with that in a pure fluid correlation with mixture properties [2]. The differences in the predicted heat transfer coefficients in Figure 3 and 4 are thus mainly due to inconsistencies in predicting the convective flow boiling contribution. The classical wide-boiling correlations by Wettermann and Steiner [15] and Jung et al. [2] predict reasonably similar results and are close to the pool boiling extensions to flow boiling, for which the Gungor and Winterton [1] pure fluid correlation was used.

For the above reasons, it is difficult to claim that one method is more appropriate to use than others. The simple Mishra et al. [11] type correlations should be avoided, since these are usually narrowed down to small concentration ranges. It is not important to use an ammonia-water specific pool boiling correlation to predict the nucleate boiling mixture degradation, because the convective boiling contribution dominates for the investigated design conditions. Thus, classical wide-boiling mixture correlations may be used as well.

\section{Conclusion}

This paper presents a systematic comparison of several flow boiling prediction methods aimed towards the ammonia-water mixtures, in an attempt to quantify their individual influence during heat exchanger design. These prediction methods include: (1) the simple Mishra et al. [11] type correlation, applied/refittet to flow boiling experimental data of ammonia-water mixtures within a narrow composition range, (2) the ammonia-water specific pool boiling correlation extensions to flow boiling using the pure fluid correlation by Gungor and Winterton [1], and (3) the classical wide-boiling correlations used directly for the ammonia-water mixture. 
Two case studies related to the use of the Kalina cycle were considered for quantifying the correlations influence on the heat exchanger design: a flue gas based heat recovery boiler (HRB) for a combined cycle power plant and a hot oil based boiler (OBB) for a solar thermal power plant.

From the heat exchanger design simulations, it may be concluded that the different flow boiling correlations resulted in small differences in the predicted heat transfer area of the evaporator, especially when excluding the simple Mishra et al. [11] type correlations. The maximum predicted evaporator area difference compared to the average were $6 \%$ and $28 \%$ for the HRB and the OBB, respectively. Excluding the simple Mishra et al. [11] type correlations and focusing on the other more elaborate correlations, then the OBB showed below $10 \%$ evaporator area difference at maximum. These simulations were performed at various ammonia-mass fractions ( 0.5 to 0.9$)$ and pressures (40 to 100 bar).

Furthermore, the heat transfer correlations employed in the current work suggest that the nucleate boiling contribution to flow boiling is small compared to the convective contribution to flow boiling for the considered boilers and conditions. Only at very low mass fluxes, low vapor qualities and high heat fluxes, the nucleate boiling contribution becomes significant for the ammonia-water mixtures in the considered range of boiler design conditions.

[1] K. E. Gungor, R. H. S. Winterton, A general correlation for flow boiling in tubes and annuli, International Journal of Heat and Mass Transfer 29 (1986) 351-358, doi:10.1016/0017-9310(86)90205-X.

[2] D. S. Jung, M. McLinden, R. Radermacher, D. Didion, A study of flow boiling heat transfer with refrigerant mixtures, International Journal of Heat and Mass Transfer 32 (9) (1989) 1751-1764, doi:10.1016/0017-9310(89)90057-4.

[3] G. P. Celata, M. Cumo, T. Setaro, A review of pool and forced convective boiling of binary-mixtures, Experimental Thermal and Fluid Science 9 (4) (1994) 367-381, doi:10.1016/0894-1777(94)90015-9.

[4] S. S. Stecco, U. Desideri, Considerations on the Design Principles for a Binary Mixture Heat Recovery Boiler, Journal of Engineering for Gas Turbines and Power 114 (4) (1992) 701-706, doi:doi:10.1115/1.2906645.

[5] R. Tillner-Roth, D. Friend, Helmholtz free energy formulation of the thermodynamic properties of the mixture \{water + ammonia\}, Journal of physical and chemical reference data 27 (1) (1998) 63 - 96 , doi:http://dx.doi.org/10.1063/1.556015.

[6] E. W. Lemmon, M. L. Huber, M. O. Mclinden, NIST Standard Reference Database 23: Reference Fluid Thermodynamic and Transport Properties - REFPROP 9.12, National Institute of Standards and Technology, Boulder, Colorado, USA, 2013. 
[7] M. Conde-Petit, Thermophysical Properties of NH3+H2O Mixtures for the Industrial Design of Absorption Refrigeration Equipment, Zurich, Switzerland, URL http : / /www •mrc-eng • com, 2006, Accessed 26 January 2015.

[8] M. R. Kærn, A. Modi, J. K. Jensen, F. Haglind, An assessment of transport property estimation methods for ammonia-water mixtures and their influence on heat exchanger size, International Journal of Thermophysics, In Press, Accepted Manuscript (2015) .

[9] W. Rivera, R. Best, Boiling heat transfer coefficients inside a vertical smooth tube for water/ammonia and ammonia lithium nitrate mixtures, International Journal of Heat and Mass Transfer 42 (5) (1999) 905-921, doi:10.1016/S0017-9310(98)00211-7.

[10] T. Khir, R. K. Rahim, N. Ghaffour, A. B. Brahim, Experimental study on forved convective boiling of ammonia - water mixtures in a vertical smooth tube, The Arabian Journal for Science and Engineering 30 (1B) (2005) 47-63, ISSN 1319-8025.

[11] M. P. Mishra, H. K. Varma, C. P. Sharma, Heat transfer coefficients in forced convection evaporation of refrigerants mixtures, Letters in Heat and Mass Transfer 8 (2) (1981) 127 - 136, doi:10.1016/0094-4548(81)90034-5.

[12] H. Arima, A. Okamoto, Y. Ikegami, Local boiling heat transfer characteristics of ammonia/water binary mixture in a vertical plate evaporator, International Journal of Refrigeration 34 (3) (2011) 648-657, doi:10.1016/j.ijrefrig.2010.12.015.

[13] F. Táboas, M. Vallès, M. Bourouis, A. Coronas, Flow boiling heat transfer of ammonia/water mixture in a plate heat exchanger, International Journal of Refrigeration 33 (4) (2010) 695-705, doi:10.1016/j.ijrefrig.2009.12.005.

[14] F. Táboas, M. Vallès, M. Bourouis, A. Coronas, Assessment of boiling heat transfer and pressure drop correlations of ammonia/water mixture in a plate heat exchanger, International Journal of Refrigeration 35 (3) (2012) 633-644, doi:10.1016/j.ijrefrig.2011.10.003.

[15] M. Wettermann, D. Steiner, Flow boiling heat transfer characteristics of wide-boiling mixtures, International Journal of Thermal Sciences 39 (2) (2000) 225-235, doi:10.1016/S1290-0729(00)00241-6.

[16] J. W. Palen, Shell-and-Tube Reboilers, in: E. U. Schlünder (Ed.), Heat Exchanger Design Handbook, chap. 3, Hemisphere, Washington, D.C., USA, ISBN 0891161252, 3.6.1-3.6.4, 1983.

[17] J. R. Thome, Boiling of new refrigerants: a state-of-the-art review, International Journal of Refrigeration 19 (7) (1996) 435-457, doi:10.1016/S0140-7007(96)00004-7.

[18] A. Modi, F. Haglind, Performance analysis of a Kalina cycle for a central receiver solar thermal power plant with direct steam generation, Applied Thermal Engineering 65 (1-2) (2014) 201-208, doi:10.1016/j.applthermaleng.2014.01.010.

[19] K. Stephan, Two-phase heat exchange for new refrigerants and their mixtures, International Journal of Refrigeration 18 (3) (1995) 198 - 209, doi:10.1016/0140-7007(95)90315-Q. 
[20] D. Kenning, New developments in pool boiling, International Journal of Refrigeration 20 (8) (1997) 534 - 544, doi:10.1016/S0140-7007(97)00068-6.

[21] L. Cheng, D. Mewes, Review of two-phase flow and flow boiling of mixtures in small and mini channels, International Journal of Multiphase Flow 32 (2) (2006) 183-207, doi:10.1016/j.ijmultiphaseflow.2005.10.001.

[22] S. Grauso, R. Mastrullo, A. Mauro, G. Vanoli, CO2 and propane blends: Experiments and assessment of predictive methods for flow boiling in horizontal tubes, International Journal of Refrigeration 34 (4) (2011) 1028-1039, doi:10.1016/j.ijrefrig.2011.03.001.

[23] M. B. Ibrahim, R. M. Kovach, A Kalina cycle application for power generation, Energy 18 (9) (1993) 961-969, doi:10.1016/S0360-5442(06)80001-0.

[24] P. Nag, A. Gupta, Exergy analysis of the Kalina cycle, Applied Thermal Engineering 18 (6) (1998) 427-439, doi:10.1016/S1359-4311(97)00047-1.

[25] J. R. Thome, S. Shakir, New correlation for nucleate pool boiling of aqueous mixtures, AIChE Symposium Series 83 (257) (1987) 46 - 51, ISSN 00658812.

[26] K. E. Gungor, R. H. S. Winterton, Simplified general correlation for saturated flow boiling and comparison of correlations with data, Chemical Engineering Research and Design 65 (1987) 148-156, ISSN 02638762.

[27] F. W. Dittus, L. M. K. Boelter, Heat transfer in automobile radiators of the tubular type, University of California Publications in Engineering 2 (13) (1930) 443-461.

[28] G. P. Celata, M. Cumo, T. Setaro, Forced convective boiling in binary mixtures, International Journal of Heat and Mass Transfer 36 (13) (1993) 3299-3309, doi:10.1016/0017-9310(93)90012-U.

[29] D. L. Bennett, J. C. Chen, Forced convective boiling in vertical tubes for saturated pure components and binary mixtures, AIChE Journal 26 (3) (1980) 454 - 461, ISSN 15475905.

[30] K. Stephan, M. Körner, Berechnung des Wärmeübergangs verdampfender binärer Flüssigkeitsgemische, Chemie Ingenieur Technik 41 (7) (1969) 409-417, doi:10.1002/cite.330410702.

[31] W. F. Calus, P. Rice, Pool boiling - binary liquid mixtures, Checmical Engineering Science 27 (9) (1972) 16871697, doi:10.1016/0009-2509(72)80083-6.

[32] H. Jungnickel, P. Wassilew, W. Kraus, Investigations on the heat transfer of boiling binary refrigerant mixtures, International Journal of Refrigeration 3 (3) (1980) 129-133, doi:10.1016/0140-7007(80)90092-4.

[33] E. U. Schlünder, Heat transfer in nucleate boiling of mixtures, International Chemical Engineering 23 (4) (1983) 589 - 599, ISSN 00206318.

[34] Y. Fujita, M. Tsutsui, Heat transfer in nucleate pool boiling of binary mixtures, International Journal of Heat and Mass Transfer 37 (1994) 291-302, doi:10.1016/0017-9310(94)90030-2.

[35] Y. Fujita, M. Tsutsui, Heat Transfer in Nucleate Boiling of Binary Mixtures: Development of a Heat Transfer Correlation, JSME International Journal Series B 40 (1) (1997) 134 - 141, doi:10.1299/jsmeb.40.134.

[36] T. Inoue, N. Kawae, M. Monde, Characteristics of heat transfer coefficient during nucleate pool boiling of binary 
mixtures, Heat and Mass Transfer 33 (4) (1998) 337-344, doi:10.1007/s002310050199.

[37] G. Vinayak Rao, A. Balakrishnan, Heat transfer in nucleate pool boiling of multicomponent mixtures, Experimental Thermal and Fluid Science 29 (1) (2004) 87-103, doi:10.1016/j.expthermflusci.2004.02.001.

[38] H. Arima, M. Monde, Y. Mitsutake, Heat transfer in pool boiling of ammonia/water mixture, Heat and Mass Transfer 39 (7) (2003) 535-543, doi:10.1007/s00231-002-0302-2.

[39] F. Táboas, M. Vallès, M. Bourouis, A. Coronas, Pool boiling of ammonia/water and its pure components: Comparison of experimental data in the literature with the predictions of standard correlations, International Journal of Refrigeration 30 (5) (2007) 778-788, doi:10.1016/j.ijrefrig.2006.12.009.

[40] T. Inoue, M. Monde, Prediction of pool boiling heat transfer coefficient in ammonia/water mixtures, Heat Transfer-Asian Research 38 (2) (2009) 65-72, doi:10.1002/htj.20234.

[41] a. Sathyabhama, T. A. Babu, Experimental investigation in pool boiling heat transfer of ammonia/water mixture and heat transfer correlations, International Journal of Heat and Fluid Flow 32 (3) (2011) 719-729, doi:10.1016/j.ijheatfluidflow.2011.02.007.

[42] T. Inoue, M. Monde, Y. Teruya, Pool boiling heat transfer in binary mixtures of ammonia/water, International Journal of Heat and Mass Transfer 45 (2002) 4409-4415, doi:10.1016/S0017-9310(02)00153-9.

[43] K. Nishikawa, Y. Fujita, On the pressure factor in nucleate boiling heat transfer, Memoirs of the Faculty of Engineering, Kyushu University 36 (4) (1977) 303 - 341, ISSN 00236160.

[44] I. Mostinski, Application of the Rule of Corresponding States for Calculation of Heat Transfer and Critical Heat Flux to Boiling Liquids, Teploenergetika 4 (1963) 66.

[45] K. Stephan, M. Abdelsalam, Heat-transfer correlations for natural convection boiling, International Journal of Heat and Mass Transfer 23 (1) (1980) 73 - 87, doi:10.1016/0017-9310(80)90140-4.

[46] M. G. Cooper, Heat Flow Rates in Saturated Nucleate Pool Boiling-A Wide-Ranging Examination Using Reduced Properties, Advances in Heat Transfer 16 (1984) 157 - 239, doi:10.1016/S0065-2717(08)70205-3.

[47] D. Gorenflo, D. Kenning, Pool Boiling, in: V. D. Ingenieure (Ed.), VDI Heat Atlas, chap. H.2, Springer-Verlag Berlin Heidelberg, (English version), 2 edn., 1585, 2010.

[48] K. Nishikawa, Y. Fujita, Nucleate Boiling Heat Transfer and Its Augmentation, Advances in Heat Transfer 20 (1990) 1-82, doi:10.1016/S0065-2717(08)70025-X.

[49] K. Nishikawa, Y. Fujita, H. Ohta, S. Hidaka, Effect of the surface roughness on the nucleate boiling heat transfer over the wide range of pressure, in: 7th International Heat Transfer Conference, ISBN 0891162992, 61 - 66, 1982.

[50] A. Sathyabhama, R. Hegde, Prediction of nucleate pool boiling heat transfer coefficient, Thermal Science 14 (2) (2010) 353-364, doi:10.2298/TSCI1002353S.

[51] J. R. Thome, Prediction of the mixture effect on boiling in vertical thermosyphon reboilers, Heat Transfer Engineering 10 (2) (1989) 29 - 38, doi:10.1080/01457638908939696. 
[52] J. C. Chen, Correlation for Boiling Heat Transfer to Saturated Fluids in Convective Flow, Industrial \& Engineering Chemistry Process Design and Development 5 (3) (1966) 322-329, doi:10.1021/i260019a023.

[53] J. Palen, W. Small, A new way to design kettle and internal reboilers, Hydrocarbon Processing and Petroleum Refiner 43 (11) (1964) 199 - 208, ISSN 00962406.

[54] G. Orian, M. Jelinek, A. Levy, Flow boiling of binary solution in horizontal tube, Energy 35 (1) (2010) 35-44, doi:10.1016/j.energy.2009.08.024.

[55] J. M. Cho, Y. J. Kim, M. S. Kim, Experimental studies on the characteristics of evaporative heat transfer and pressure drop of $\mathrm{CO} 2 /$ propane mixtures in horizontal and vertical smooth and micro-fin tubes, International Journal of Refrigeration 33 (1) (2010) 170-179, doi:10.1016/j.ijrefrig.2009.09.009.

[56] D. Steiner, J. Taborek, Flow Boiling Heat Transfer in Vertical Tubes Correlated by an Asymptotic Model, Heat Transfer Engineering 13 (2) (1992) 43 - 69, doi:10.1080/01457639208939774.

[57] H. Ünal, Prediction of nucleate pool boiling heat transfer coefficients for binary mixtures, International Journal of Heat and Mass Transfer 29 (4) (1986) 637 - 640, doi:10.1016/0017-9310(86)90096-7.

[58] E. W. Lemmon, Private communication, National Institute of Standards and Technology, Boulder, Colorado, USA, 2013.

[59] A. Modi, F. Haglind, Thermodynamic optimisation and analysis of four Kalina cycle layouts for high temperature applications, Applied Thermal Engineering 76 (2015) 196-205, doi:10.1016/j.applthermaleng.2014.11.047.

[60] Dymola 2014, Dynamic Modeling Laboratory, Dassault Systemes AB, Research Park Ideon SE-223 70, Lund, Sweden, 2014.

[61] J. Wronski, M. R. Kærn, H. Francke, REFPROP2Modelica, Technical University of Denmark and GFZ Potsdam, URL https://github.com/jowr/REFPROP2Modelica, Accessed 26 January 2015.

[62] D. E. Briggs, E. H. Young, Convection heat transfer and pressure drop of air flowing across triangular pitch banks of finned tubes, Chemical Engineering Progress Symposium Series 59 (41) (1963) 1-10, ISSN 00692948.

[63] R. K. Shah, D. P. Sekulic, Fundamentals of heat exchanger design, John Wiley \& Sons, Hoboken, New Jersey, USA, ISBN 1615833285, 2003.

[64] K. K. Robinson, D. E. Briggs, Pressure drop of air flowing across triangular pitch banks of finned tubes, Chemical Engineering Progress Symposium Series 62 (64) (1966) 177-184, ISSN 00692948.

[65] V. Gnielinski, New equation for heat and mass transfer in turbulent pipe and channel flow, International Chemical Engineering 16 (1976) 359-368.

[66] H. Blasius, Das Aehnlichkeitsgesetz bei Reibungsvorgängen in Flüssigkeiten, in: Mitteilungen über Forschungsarbeiten auf dem Gebiete des Ingenieurwesens 131, Springer, Berlin, Germany, 1-41, 1913.

[67] H. Müller-Steinhagen, K. Heck, A Simple Friction Pressure Drop Correlation for Two-Phase Flow in Pipes, Chemical Engineering and Processing: Process Intensification 20 (1986) 297-308.

[68] Solutia Inc., Therminol 66, High performance highly stable heat transfer fluid, URL 
http://twt.mpei.ac.ru/, 2014, Accessed 26 January 2015.

2 [69] J. Taborek, Shell-and-tube heat exchangers: single phase flow, in: G. F. Hewitt (Ed.), Heat Exchanger Design Handbook, chap. 3, Begell House, New York, USA, ISBN 9781567000986, 3.3.3-1 - 3.3.11-5, 1998. 